Key Words:

Grout Flow Patterns, Bingham Plastic Model, Grout Pouring Height

\title{
Retention:
}

Permanent

\section{SALTSTONE SDU6 MODELING STUDY}

JULY 2012

Savannah River National Laboratory

Savannah River Nuclear Solutions

Aiken, SC 29808

Prepared for the U.S. Department of Energy Under

Contract Number DE-AC09-08SR22470

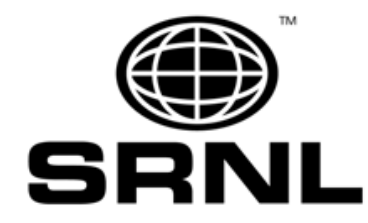




\section{DISCLAIMER}

This work was prepared under an agreement with and funded by the U.S. Government. Neither the U. S. Government or its employees, nor any of its contractors, subcontractors or their employees, makes any express or implied:

1. warranty or assumes any legal liability for the accuracy, completeness, or for the use or results of such use of any information, product, or process disclosed; or

2. representation that such use or results of such use would not infringe privately owned rights; or

3. endorsement or recommendation of any specifically identified commercial product, process, or service.

Any views and opinions of authors expressed in this work do not necessarily state or reflect those of the United States Government, or its contractors, or subcontractors.

Printed in the United States of America

Prepared for

U.S. Department of Energy 
Key Words:

Grout Flow Patterns, Bingham Plastic Model, Grout Pouring Height

Retention:

Permanent

\title{
SALTSTONE SDU6 MODELING STUDY
}

\author{
Si Y. Lee \\ Sinjae Hyun* \\ *Professor in Mercer University
}

JULY 2012

Savannah River National Laboratory

Savannah River Nuclear Solutions

Savannah River Site

Aiken, SC 29808 
SRNL-STI-2012-00454

- ii - 


\section{TABLE OF CONTENTS}

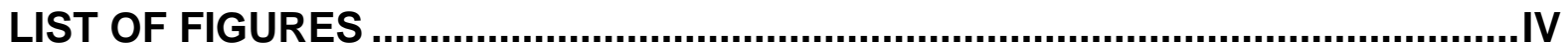

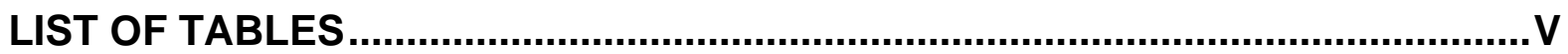

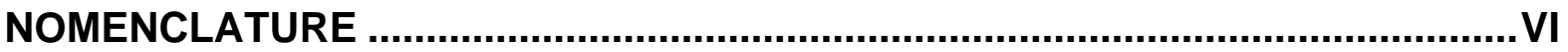

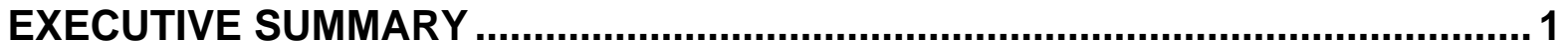

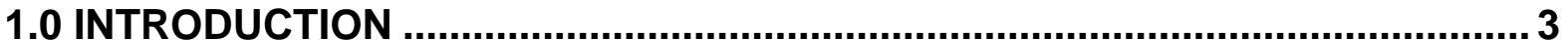

2.0 SOLUTION APPROACH AND MODELING ASSUMPTIONS ........................... 5

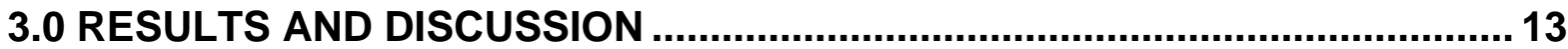

3.1 BINGHAM PLASTIC MODELING RESULTS .....................................................13

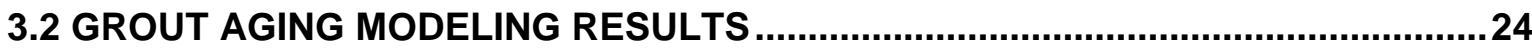

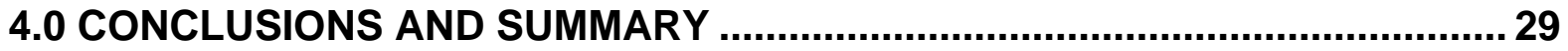

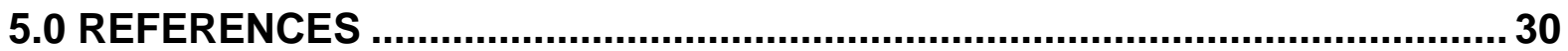




\section{LIST OF FIGURES}

Figure 1. Geometrical configurations for the Saltstone Disposal Unit \#6 for the baseline modeling analysis (M-TC-Z-00008)........................................................... 4

Figure 2. Bingham plastic model used in the present analysis ..................................... 7

Figure 3. Computational domain used for the baseline modeling calculations ...................12

Figure 4. Three-dimensional hexahedral meshes used for the modeling calculations ........12

Figure 5. Comparison of transient grout accumulation results for $150 \mathrm{gpm}$ feed flow at $5 \mathrm{ft}$ pouring height, indicating that red zone has $100 \%$ grout volume fraction..........16

Figure 6. Flow patterns and profiles of grout volume fractions and viscosity near the center of the grout pouring region at 30 minutes transient time for $2.07 \mathrm{~m} / \mathrm{sec}$ discharge velocity from $5 \mathrm{ft}$ elevation above the SDU floor. ....................................... 17

Figure 7. Comparison of transient shapes of the grout layer accumulated on the floor between two different pouring heights near the grout impinging region at 30 minutes' transient time, indicating the red region to be $100 \%$ grout.

Figure 8. Comparison of transient radial distances from pouring point for two different pouring heights ( $5 \mathrm{ft}$ and $43 \mathrm{ft}$ elevations) during early pouring period............. 19

Figure 9. Comparison of transient shape of grout accumulation layer near the pouring point for $43 \mathrm{ft}$ pouring height. ......................................................................... 20

Figure 10. Comparison of transient radial distances from pouring point for two different pouring heights ( $5 \mathrm{ft}$ and $43 \mathrm{ft}$ elevations).

Figure 11. Comparison of transient grout volume fractions for $5 \mathrm{ft}$ pouring elevation along the vertical distance from the floor at the radial distance of one meter.

Figure 12. Comparison of transient grout volume fractions for two different heights of pouring port along the vertical distance from the floor at the radial distance of one meter.

Figure 13. Comparison of transient grout volume fractions for two different heights of pouring port along the horizontal distance from the pouring center at the 0.5 inches above the floor.

Figure 14. Comparison of transient radial distances from pouring point for two different pouring heights ( $5 \mathrm{ft}$ and $43 \mathrm{ft}$ elevations) under two different non-Newtonian models.

Figure 15. Comparison of transient radial distances for two different pouring heights (5 ft and $43 \mathrm{ft}$ elevations) for different viscosities from grout thixotropic model.........27

Figure 16. Distribution of grout volume fraction along the vertical line at $r=8.25 \mathrm{ft}$ from the center for $5 \mathrm{ft}$ pouring elevation and $60 \mathrm{cP}$ nominal viscosity case.....

Figure 17. Distribution of grout volume fraction along the vertical line at $r=8.25 \mathrm{ft}$ from the center for $5 \mathrm{ft}$ pouring elevation and $120 \mathrm{cP}$ nominal viscosity case.

Figure 18. Averaged grout volume fraction comparison between two different viscosity cases. 


\section{LIST OF TABLES}

Table 1. Nominal design and operating conditions for the analysis .............................. 5

Table 2. Modeling cases considered for the analysis .......................................... 10

Table 3. Comparison of transient accumulation thickness on the SDU floor for two different

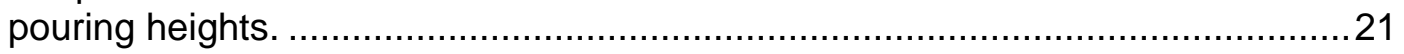

Table 4. Comparison of transient grout volume fractions for the grout layer on the SDU floor

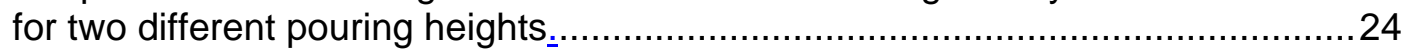




\section{NOMENCLATURE}

\begin{tabular}{|c|c|}
\hline$A$ & Area \\
\hline $\mathrm{C}_{\mu}$ & Turbulent viscosity coefficient \\
\hline D & Tank diameter \\
\hline $\mathrm{ft}$ or feet & Feet ( = $0.3048 \mathrm{~m})$ \\
\hline g & Gravitational acceleration \\
\hline $\mathrm{H}$ & Height for Saltstone disposal unit \\
\hline$h_{d}$ & Discharge height \\
\hline $\mathrm{k}$ & Kinetic energy or consistency \\
\hline$P$ & Turbulent production rate or power consumption \\
\hline $\mathrm{p}$ & Pressure \\
\hline$\Delta \mathrm{p}$ & Pressure drop \\
\hline $\mathrm{Q}$ & Volumetric flow rate \\
\hline$r_{d}$ & Discharge radius \\
\hline $\mathrm{R}$ & Radius for Saltstone disposal unit \\
\hline$U$ & Maximum downward velocity \\
\hline$u$ & Local velocity along the $x$-axis \\
\hline $\mathrm{v}$ & Local velocity along the y-axis \\
\hline w & Local velocity along the z-axis \\
\hline$x$ & Local distance along the $x$-axis \\
\hline y & Local distance along the $y$-axis \\
\hline z & Local distance along the $z$-axis \\
\hline$\alpha$ & Volume fraction for grout material \\
\hline$\rho_{f}$ & Grout fluid density \\
\hline$\rho$ & Mixture density \\
\hline$v$ & Kinematic viscosity \\
\hline$v_{\mathrm{t}}$ & Turbulent kinematic viscosity \\
\hline$\tau$ & Shear stress \\
\hline$\kappa$ & Turbulent kinetic energy per unit mass \\
\hline$\varepsilon$ & Turbulent energy dissipation rate per unit mass \\
\hline$\tau_{0}$ & Yield stress \\
\hline$T^{\prime}$ & Turbulent energy transport \\
\hline$\sigma_{k}$ & Turbulent Prandtl number \\
\hline$\eta_{\infty}$ & Plastic viscosity or consistency \\
\hline$\dot{\gamma}$ & Shear rate \\
\hline$\mu$ & Dynamic viscosity \\
\hline In or inch & $\operatorname{Inch}(=0.0254 \mathrm{~m})$ \\
\hline $\mathrm{Re}$ & Reynolds number \\
\hline CFD & Computational Fluid Dynamics \\
\hline CFX & CFD software code \\
\hline DOE & United States Department of Energy \\
\hline FLUENT & CFD software code \\
\hline SRS & Savannah River Site \\
\hline SWPF & Salt Waste Processing Facility \\
\hline
\end{tabular}




\section{EXECUTIVE SUMMARY}

A new disposal unit, designated as Saltstone Disposal Unit 6 (SDU6), is being designed for support of site accelerated closure goals and salt waste projections identified in the new Liquid Waste System Plan. The unit is a cylindrical disposal cell of $375 \mathrm{ft}$ in diameter and 43 $\mathrm{ft}$ in height, and it has a minimum 30 million gallons of capacity. SRNL was requested to evaluate the impact of an increased grout placement height on the flow patterns radially spread on the floor and to determine whether grout quality is impacted by the height. The primary goals of the work are to develop the baseline Computational Fluid Dynamics (CFD) model and to perform the evaluations for the flow patterns of grout material in SDU6 as a function of elevation of grout discharge port and grout rheology.

Two transient grout models have been developed by taking a three-dimensional multiphase CFD approach to estimate the domain size of the grout materials radially spread on the facility floor and to perform the sensitivity analysis with respect to the baseline design and operating conditions such as elevation height of the discharge port and fresh grout properties. For the CFD modeling calculations, air-grout Volume of Fluid (VOF) method combined with Bingham plastic and time-dependent grout models were used for examining the impact of fluid spread performance for the initial baseline configurations and to evaluate the impact of grout pouring height on grout quality. The grout quality was estimated in terms of the air volume fraction for the grout layer formed on the SDU6 floor, resulting in the change of grout density. The study results should be considered as preliminary scoping analyses since benchmarking analysis is not included in this task scope.

Transient analyses with the Bingham plastic model were performed with the FLUENT ${ }^{\mathrm{TM}}$ code on the high performance parallel computing platform in SRNL. The analysis coupled with a transient grout aging model was performed by using ANSYS-CFX code in the parallel computing platform in Mercer University. Recommended operational guidance was developed assuming that local shear rates and flow patterns related to radial spread along the SDU floor can be used as a measure of grout performance and spatial dispersion affected by the grout height and viscosity.

The main conclusions drawn from the grout modeling and calculations are as follows:

- The $5 \mathrm{ft}$ height baseline results show that when the $150 \mathrm{gpm}$ grout flow with a $5 \mathrm{~Pa}$ yield stress and a $60 \mathrm{cp}$ viscosity is poured down through a 3 inch discharge port, the grout is spread radially up to about $64 \mathrm{ft}$ distance from the pouring center after 2 hours' pouring time. The air volume fraction of the grout layer is about $29 \%$ at 5 minutes' transient time, and it is reduced by about $9 \%$ in 2 hours' pouring time, resulting in the grout density consisting of about $80 \%$ grout and $20 \%$ air volume fractions.

- The sensitivity results show that when the discharge port is located at a higher position, a larger amount of air is trapped inside the layer formed below the discharge port at the early transient time of less than 30 minutes because of the higher impinging momentum of the grout flow on the floor, resulting in the formation of less smooth layer.

- The results clearly indicate that the radial spread for the $43 \mathrm{ft}$ discharge port is about $10 \%$ faster than that of the $5 \mathrm{ft}$ discharge port for the early transient period of 5 minutes. However, for the pouring time longer than half an hour, the discharge port height does not affect the radial distance spread on the disposal floor.

- When grout quality is related to grout volume fraction, the grout volume fraction for the $43 \mathrm{ft}$ discharge port has lower volume fraction than the $5 \mathrm{ft}$ discharge port for the 
transient period of the first 5 minutes. However, for the pouring time longer than half an hour, the discharge port height does not affect the grout volume fraction for the layer accumulated on the disposal floor.

- A modified Bingham plastic model coupled with time-dependent viscosity behavior was developed for conducting the initial scoping calculations to assess the impact of fluid residence time on radial spreading and basic flow patterns.

- The results for the transient viscosity model show that when grout material becomes more viscous, the thickness of the grout layer accumulated on the floor becomes higher, but the radial distance spread on the horizontal floor becomes smaller. The early transient results for the grout density with about $32 \%$ air volume fractions are in reasonable agreement with those of the idealized Bingham plastic model.

- It is recommended that the current models developed here be benchmarked against the experimental results for critical applications of the modeling results. 


\subsection{INTRODUCTION}

A new disposal unit, designated as Salt Disposal Unit 6 (SDU6), is being designed for support of site accelerated closure goals and salt waste projections identified in the new Liquid Waste System Plan [1]. The unit is a cylindrical disposal vault of $375 \mathrm{ft}$ (average) in diameter and $43 \mathrm{ft}$ in height, and it has a minimum 30 million gallons of capacity [1]. SRNL was tasked to evaluate an increased grout placement height and determine whether grout quality is impacted [1,2]. The primary goals are to develop the baseline computational fluid dynamics (CFD) model and to perform the evaluations for the flow patterns of grout material in SDU6 as a function of elevation of grout discharge port and grout rheology. The modeling domain is schematically shown in Fig. 1. A Bingham Plastic flow model is used as a baseline performance analysis to represent the grout flow behavior for the SDU6 facility. A twophase modeling approach is taken by considering two fluids of air and grout for the entire space of the facility. In this case, the grout fluid is modeled as a single-phase homogeneous mixture. This approach assumes that the air-grout interface will determine the shape of the accumulation mound. A transient method is used to simulate sequential pours on top of accumulated material.

The SDU6 Engineering Team has identified a technical gap for the increased grout placement height and its impact on grout quality [3]. A CFD simulation study was performed to evaluate the flow pattern behavior driven by flow impingement and gravity along the horizontal floor and to estimate the grout flow radius from the pour location in SDU6. The grout flow radius is designated as the parameter $r$ in Fig. 1. The results of this study will be used to develop the design guidelines for the SDU6 grout discharge ports.

The objectives of the simulation study are to:

- Estimate the domain size of the grout materials radially spread on the facility floor under the baseline modeling conditions as shown in Table 1.

- Perform the sensitivity analysis with respect to the baseline design and operating conditions such as elevation of the discharge port, discharge pipe diameter, and fresh grout properties.

- Determine the changes in grout density as it is related to grout drop height.

A three-dimensional CFD two-phase modeling method with a symmetric boundary will be used for computational efficiency to achieve the objectives. Based on the design and operating conditions discussed earlier, a transient computational approach was taken to compute flow fields mainly driven by pumping inertia and natural gravity. The main solution methodologies and modeling assumptions are as follows:

- The nominal modeling domain will be a SDU6 configuration equipped with a single discharge port located at $5 \mathrm{ft}$ or $43 \mathrm{ft}$ above the floor as shown in Fig. 1 and Table 1.

- The modeling simulations will use axi-symmetric, two-component air-grout, isothermal governing equations with a volume-of-fluid (VOF) approach.

- A Bingham Plastic flow model will be used to capture the non-Newtonian grout flow behavior.

- For the transient model, the top liquid surface was assumed to be at atmospheric pressure. 


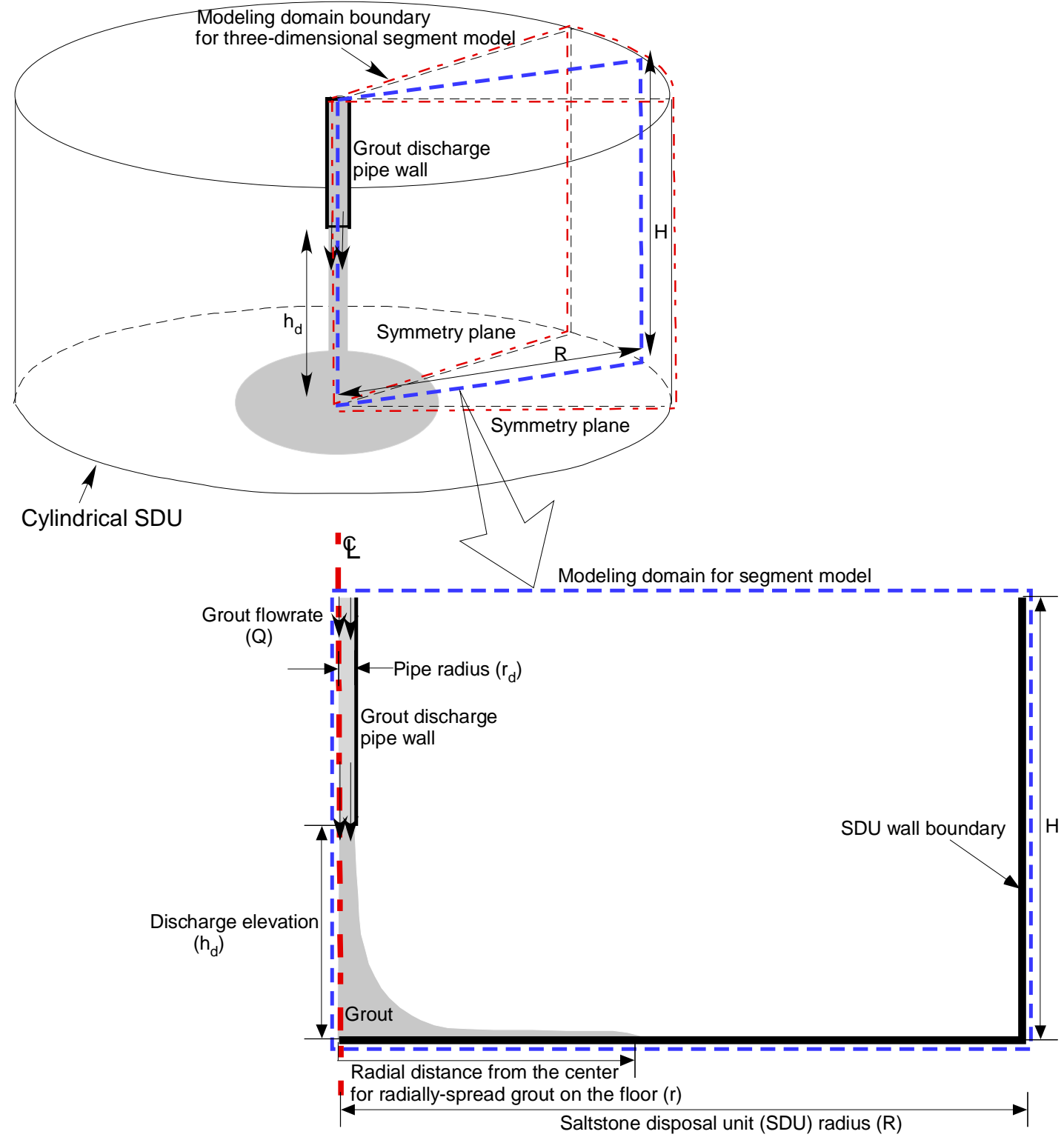

Note: Discharge pipe elevation $\left(h_{d}\right)$ ranges from $5 \mathrm{ft}$ up to 43 feet.

Figure 1. Geometrical configurations of SDU6 for the baseline modeling analysis (M-TC-Z00008) 
Table 1. Nominal design and operating conditions for the analysis

\begin{tabular}{|c|c|c|}
\hline Parameters & & Modeling input \\
\hline \multirow{2}{*}{$\begin{array}{l}\text { SDU \#6 facility } \\
\text { dimensions }\end{array}$} & Diameter in average & $375 \mathrm{ft}$ \\
\hline & Height $(H)$ & $43 \mathrm{ft}$ \\
\hline \multirow{4}{*}{ Grout discharge } & Pipe exit radius $\left(r_{d}\right)$ & 1.5 in \\
\hline & Discharge elevation $\left(h_{d}\right)$ & $\begin{array}{c}43 \mathrm{ft}-\text { maximum } \\
\text { (nominal: } 5 \mathrm{ft} \text { and } 43 \mathrm{ft} \text { ) } \\
\text { (Discharge point elevation } \\
\text { range }-5 \mathrm{ft} \text { to } 43 \mathrm{ft} \text { ) }\end{array}$ \\
\hline & Grout discharge flowrate (Q) & $150 \mathrm{gpm}$ \\
\hline & Average grout velocity at pipe exit & $6.808 \mathrm{ft} / \mathrm{sec}$ \\
\hline \multirow{4}{*}{$\begin{array}{l}\text { Material } \\
\text { properties }\end{array}$} & Specific gravity & $1.63 \sim 1.74$ (nominal: 1.7$)$ \\
\hline & Apparent viscosity & $\begin{array}{c}40 \sim 203 \mathrm{cp} \text { (nominal: } 60 \mathrm{cp} \text {, } \\
120 \mathrm{cp})\end{array}$ \\
\hline & Yield stress & $2 \sim 11 \mathrm{~Pa}$ (nominal: $5 \mathrm{~Pa}$ ) \\
\hline & Surface tension (N/m) & 0.06 \\
\hline
\end{tabular}

Note:*Viscosity corresponding to 25 wt\% salt solution [SRNL-STI-2011-00346 and E-mail sent by C. L. Langton, May 9, 2012]

\subsection{SOLUTION APPROACH AND MODELING ASSUMPTIONS}

Based on the design and operating conditions discussed earlier, a transient air-grout VOF multiphase approach was taken to compute radial flow fields spread on the horizontal floor when $150 \mathrm{gpm}$ grout flow through a 3-inch pipe is poured into $375 \mathrm{ft}$ cylindrical vault at different elevations. The geometrical configurations for the modeling domain are shown in Fig. 1. The modeling simulations used three-dimensional transient, isothermal governing equations.

The VOF model can model two or more immiscible fluids by solving a single set of momentum equations and tracking the volume fraction of each of the fluids throughout the domain. Typical application includes the prediction of jet breakup, the motion of large bubbles in a liquid, the motion of liquid after a dam break, and the steady or transient tracking of any liquid-gas interface. The VOF formulation relies on the fact that two fluids of air and grout are not interpenetrating. For each phase, a variable is introduced as the volume fraction of the phase in the computational cell. In each control volume, the volume fractions of two phases sum to unity. The fields for all variables and properties are shared by the phases and represent volume-averaged values, as long as the volume fraction of each 
of the phases is known at each location. Thus the variables and properties in any given cell are either purely representative of one of the phases, or representative of a mixture of the phases, depending upon the volume fraction values. In other words, if the grout volume fraction in the cell is denoted as $\alpha$, then the following three conditions are possible: for zero fraction of volume, the cell is empty, and for unity of $\alpha$, the cell is full of grout. When grout volume fraction is less than 1, the cell contains the interface between the grout and air. Based on the local value of grout volume fraction, the appropriate properties and variables will be assigned to each control volume within the domain. The VOF model also considers the effects of surface tension of grout against air along the interface.

For the numerical modeling and calculations, three-dimensional transient two-component mixture momentum and continuity equations were used as the basic governing equations to estimate fluid motion. Hydraulic flow regime conditions were determined by estimating the Reynolds number corresponding to the operating conditions of a grout pouring rate considered for the Saltstone modeling study. The flow domain driven by the nominal flowrate of $150 \mathrm{gpm}$ through 3 inch pipe is turbulent in terms of Reynolds number, which corresponds to 4,500. For the analysis, a standard two-equation turbulence model, referred to as the $\kappa-\varepsilon$ model in the literature, is used to capture turbulent eddy motion due to the grout impingement on the floor.

For incompressible transient flow, the equation of the continuity for grout flow is

$$
\frac{\partial\left(\alpha \rho_{f}\right)}{\partial t}+\nabla \bullet\left(\alpha \rho_{f} \vec{v}_{f}\right)=0
$$

In Eq. (1) the subscript $f$ indicates grout fluid. When air and grout components are homogeneously mixed in each of the computational cells for the VOF model, equation of the fluid mixture motion is

$$
\frac{\partial(\rho \vec{v})}{\partial t}+\nabla \cdot(\rho \vec{v} \vec{v})=-\nabla P+(\nabla \cdot \tau)+\rho \vec{g}
$$

The shear force term in Eq (2) becomes

$$
\begin{aligned}
(\nabla \cdot \tau) & =\mu \nabla \cdot(\nabla \vec{v}) \\
& =\mu \nabla(\nabla \cdot \vec{v})-\mu \nabla \times(\nabla \times \vec{v}) \\
& =\mu \nabla(\nabla \cdot \vec{v})-\mu \nabla \times \vec{\Omega}
\end{aligned}
$$

It is noted that the shear term drives fluid rotation as shown in the second term of the right hand side in Eq. (3). The shear term on the right hand side of the equation requires fluid viscosity. The viscosity is the ability of a material to resist flow. A higher viscosity is characteristic of a less flowable suspension. The stress tensor can be expressed as

$$
\bar{\tau}=-\vec{\eta}(\dot{\gamma}) \dot{\gamma}
$$

where $\dot{\gamma}=\nabla v+(\nabla v)^{T}$ is the rate of strain tensor and the superscript $T$ denotes matrix transpose. 
The Herschel-Bulkley equation combines the Bingham and power-law models assuming viscosity to be independent of shear rate with constant shear yield stress. The equation type is

$\tau=\tau_{o}+k \dot{\gamma}^{n}$

where $\tau_{o}$ and $k$ in Eq. (5) are yield stress and consistency, respectively. When $\mathrm{n}$ is equal to 1 , and the transition region is assumed to be negligible, Eq. (5) corresponds to the Bingham plastic model as shown in Fig. 2. As shown in the figure, consistency $k$ becomes constant under the Bingham plastic model, that is, $k=\eta_{\infty}$.

$\tau=\tau_{0}+\eta_{\infty} \dot{\gamma}$

The transition region from shear-dependent viscosity to plastic viscosity of Newtonian fluid behavior was defined in implementing the Bingham plastic model in the computational fluid dynamics approach as schematically shown in Fig. 2. As shown in the figure, the plastic viscosity $\eta_{\infty}$ is found from the slope of the linear portion of the curve. The yield stress $\tau_{o}$, as identified in Fig. 2, is determined by extending the linear portion of the curve to the vertical coordinate axis. It is the minimum stress required for a material to start flowing and deforming.

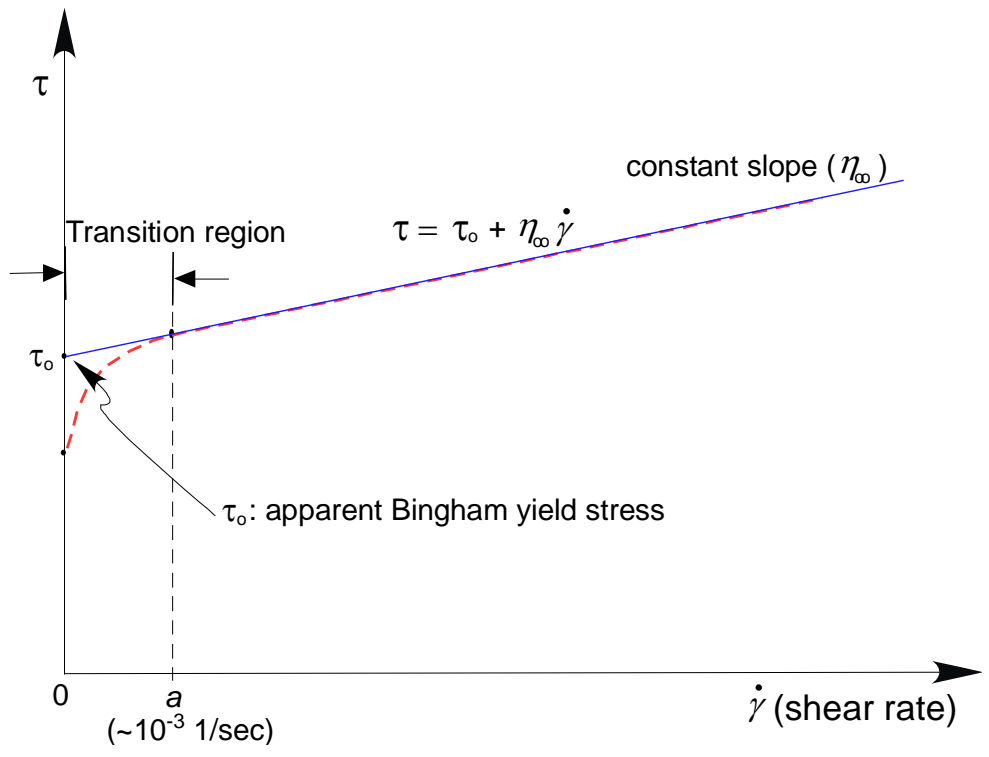

Figure 2. Bingham plastic model used in the present analysis

As discussed earlier, most of the non-Newtonian behavior of grout was calculated with a yield stress model with a single phase fluid simulation such as the Bingham plastic model with a typical yield stress. This approach was modified for simulating complex phenomena such as thixotropy, i.e., time-dependent viscosity behavior. The model used for this computational modeling task was proposed by Roussel et al. (2007) by modifying the Bingham plastic model for concrete flow. The model was modified with two additional intrinsic parameters such as the re-structuration rate of the cement mixture at rest and a destructuration parameter. 
The shear stress is defined as Bingham plastic viscosity model

$\tau=(1+\lambda) \tau_{o}+\eta_{\infty} \dot{\gamma}$

$\frac{\partial \lambda}{\partial t}=\frac{A_{t h i x}}{\tau_{0}}-\alpha \lambda \dot{\gamma}$

$\lambda$ is the structuration state of grout that evolves through the flow history. Thus, we calculated the age-of-fluid, i.e., time elapsed after pouring through the nozzle, which can be used for predicting the flow history in a Lagrangian way. From Eq. (8), $\lambda$ can be solved with a zero initial value in terms of age-of-grout $(A O G), t_{A o G}$. The concept of AoG is similar to the residence time of fluid. That is,

$\lambda=\frac{A_{t h i x}}{\alpha \tau_{0} \dot{\gamma}}\left(1-e^{-\alpha \dot{~} t_{A O G}}\right)$

Eq. (7) becomes

$\tau=\tau_{o}+\left\{\eta_{\infty}+\frac{A_{\text {thix }}}{\alpha(\dot{\gamma})^{2}}\left(1-e^{-\alpha \dot{\gamma} t_{A O G}}\right)\right\} \dot{\gamma}$

The age-of-grout (AoG), $t_{A o G}$ with time scale unit [second], is obtained from the following convective-diffusive transport equation:

$$
\frac{\partial\left(t_{A O G}\right)}{\partial t}+\frac{\partial\left(u_{i} t_{A O G}\right)}{\partial x_{i}}-\frac{\partial}{\partial x_{i}}\left[\left(\frac{v}{S c}+\frac{v_{t}}{S c_{t}}\right) \frac{\partial t_{A o G}}{\partial x_{i}}\right]=S_{\tau}
$$

where $\mathrm{u}_{\mathrm{i}}$ is the $\mathrm{i}$-directional velocity component; $v$ and $v_{t}$ are the laminar and turbulent kinematic viscosities, respectively; $\mathrm{Sc}$ is the laminar Schmidt number of a fluid; $\mathrm{Sc}_{\mathrm{t}}$ is the turbulent Schmidt number for the $t_{\mathrm{AOG}}$; and $S_{\tau}$ is the source of the $t_{\mathrm{AOG}}$. Using $\overline{\mathrm{t}_{\mathrm{AoG}}}$ instead of $t_{\mathrm{AoG}}$, Eq. (10) can be modified as follows:

$$
\frac{\partial\left(\overline{t_{A O G}}\right)}{\partial t}+\frac{\partial\left(u_{i} \overline{t_{A O G}}\right)}{\partial x_{i}}-\frac{\partial}{\partial x_{i}}\left[\left(\frac{v}{S c}+\frac{v_{t}}{S c_{t}}\right) \frac{\partial \overline{t_{A O G}}}{\partial x_{i}}\right]=1.0
$$

where $\overline{t_{A o G}}$ is equal to $t_{A o G} / S_{\tau}$. For this case, $S_{\tau}$ is 1 , and the $\overline{t_{A o G}}$ is equal to $t_{A o G}$.

For the solution of the local $t_{\mathrm{AoG}}$ indicator Eq. (12), the boundary conditions are zero [second] at the inlet and zero gradients at the exit and the wall, and the initial condition is set equal to zero [second] for the whole flow field. The $t_{A o G}$ is a passive quantity and does not affect fluid flow patterns. From Eq. (10) viscosity can be estimated as function of shear rate as well as aging of grout, $t_{\text {AoG }}$. For the scoping calculations, the modeling constants in Eq. (10), $A_{\text {thix }}$ and $\alpha$, are assumed to be $0.01 \mathrm{~Pa} / \mathrm{sec}$ and 0.1 , respectively, according to the literature information [Roussel et al., 2007].

The analysis consists of two major parts as shown in Table 2. One part is to estimate the radial distance from the pouring point by applying the Bingham plastic model to the computational domain. The nominal design and operating conditions for the modeling calculations are provided in Table 1 and Fig. 1 . The second part is to apply the Bingham plastic methodology to modeling the aging fluid simulations to evaluate the impact of fluid aging on the grout flow performance of the SDU6 for two different consistencies. The initial 
scoping results show that the flow domain driven by the nominal flowrate of $150 \mathrm{gpm}$ through a 3 inch pipe is turbulent in terms of Reynolds number, which corresponds to 4,500 .

From two key turbulence parameters of $k$ and $\varepsilon$, a quantity of turbulent eddy diffusivity $\left(k^{2} / \varepsilon\right)$, can be formed without specification of flow-dependent mixing length scale $\lambda$ [Jones and Launder, 1972]. When the turbulent energy transport term $T^{\prime}$ is modeled with a gradientdiffusion hypothesis as

$T^{\prime}=-\frac{v_{T}}{\sigma_{k}} \nabla k$

The turbulent Prandtl number for kinetic energy is generally taken to be $\sigma_{k}=1.0$. This equation assumes that there is a flux of $k$ down the gradient of $k$ due to velocity and pressure fluctuations. In summary, the transport equation for turbulent kinetic energy $k$ is

$\frac{D k}{D t}=\nabla \cdot\left(\frac{v_{T}}{\sigma_{k}} \nabla k\right)+P-\varepsilon$

The three other terms, $-D k / D t, P$, and $\varepsilon$, are in closed form given the turbulent-viscosity hypothesis.

Turbulence consists of high levels of fluctuating vorticity. At any instant, vortical motion called eddies are present in the flow. These eddies range in size from the largest geometrical scales of the flow such as tank diameter down to small eddies where molecular diffusion dominates. The eddies are continuously evolving, and the superposition of their induced motions leads to the fluctuating waves. In this situation, turbulent kinetic energy is dissipated from the largest eddies down to the smallest through a process called energy cascade.

In order to maintain the turbulence, a constant supply of energy must be fed to the turbulent fluctuations at the largest scales from the mean motions, where it is driven by a jet pump or mechanical agitator. Thus, turbulent energy dissipation rate $\varepsilon$ is viewed as the energy-flow rate in the cascade, and it is determined by the large-scale motions, independent of the viscosity at high Reynolds number. Consequently, the transport equation for $\varepsilon$ is best considered as being entirely empirical. That is,

$$
\frac{D \varepsilon}{D t}=\nabla \cdot\left(\frac{v_{T}}{\sigma_{\varepsilon}} \nabla \varepsilon\right)+C_{1}\left(\frac{\varepsilon}{k}\right) P-C_{2} \frac{\varepsilon^{2}}{k}
$$

where the turbulent viscosity is

$$
v_{T}=C_{\mu} \frac{k^{2}}{\varepsilon}
$$

where $C_{\mu}=0.09$.

It is noted that the turbulent viscosity coefficient $C_{\mu}$ of 0.09 in the two-equation model (Eq. (16)) can be derived under the log-law [Dimenna and Lee, 2011]. From these results, the two-equation turbulence model is good for the bulk model including the log-law shear region, but it will not be good for the flow within the laminar sublayer close to the wall as shown in the previous work [Lee et al., 2008]. 
Table 2. Modeling cases considered for the analysis

\begin{tabular}{|c|c|c|c|l|}
\hline Model & Cases & $\begin{array}{c}\text { Pouring } \\
\text { height (ft) }\end{array}$ & $\begin{array}{c}\text { Viscosity } \\
\text { (cp) }\end{array}$ & \multicolumn{1}{c|}{ Purposes } \\
\hline $\begin{array}{c}\text { Bingham } \\
\text { plastic model }\end{array}$ & (Baseline) & $5 \mathrm{ft}$ & 60 & $\begin{array}{l}\text { To perform the initial baseline } \\
\text { performance analysis for basic } \\
\text { flow patterns and characteristics } \\
\text { associated with radial grout } \\
\text { spreading }\end{array}$ \\
\cline { 2 - 5 } & (Sensitivity) & $43 \mathrm{ft}$ & 60 & $\begin{array}{l}\text { To perform sensitivity of grout } \\
\text { pouring height w.r.t. the scoping } \\
\text { baseline results for basic flow } \\
\text { patterns and characteristics }\end{array}$ \\
\hline $\begin{array}{c}\text { Grout aging } \\
\text { model }\end{array}$ & (Initial scoping) & $5 \mathrm{ft}$ & 60,120 & $\begin{array}{l}\text { To conduct the initial scoping } \\
\text { calculations to assess impact of } \\
\text { fluid aging impact on radial } \\
\text { spreading and basic flow patterns }\end{array}$ \\
\cline { 2 - 5 } & (Sensitivity) & $43 \mathrm{ft}$ & 60,120 & $\begin{array}{l}\text { To perform the sensitivity } \\
\text { analysis for grout pouring height } \\
\text { and viscosity under the aging } \\
\text { fluid model }\end{array}$ \\
\hline
\end{tabular}

When $150 \mathrm{gpm}$ grout flow is poured on the floor of a 375 -ft cylindrical disposal cell as shown in Fig. 1, a three-dimensional computational modeling approach was taken to compute radial grout flow fields accumulated on the floor. The transient governing equations as described previously were solved simultaneously by using a commercial CFD code, Fluent $^{\mathrm{TM}}$. A prototypic geometry for the modeling domain was created by a non-orthogonal control volume method in the CFD computational environment as shown in Fig. 3.

The analyses were based on the $10^{\circ}$ pie-type segment model for computational efficiency as shown in Fig. 4. The main solution methodologies and modeling assumptions were as follows:

- The fluid temperature is isothermally kept at $75^{\circ} \mathrm{F}$, neglecting the hydration heat generation of the cementitious material during the pouring process.

- The modeling domain is assumed to be two-component flow consisting of air and grout materials. In the analysis, the grout material is treated as a single-phase homogeneous fluid.

- The fluid behavior is assumed to follow the Bingham plastic model as discussed earlier.

- The present model was based on 375-ft cylindrical vault with no internal solid structures. 
- For the transient model, the top fluid surface was assumed to be at atmospheric pressure.

In summary, the governing equations to be solved by the CFD approach are one grout continuity equation, three air-grout mixture momentum equations for the three component directions ( $\mathrm{x}, \mathrm{y}$, and $\mathrm{z}$ directions), and two transport equations for the two turbulence quantities, namely $\kappa$ and $\varepsilon$. As a constitutive relation, the Bingham plastic model or the grout aging model is used to estimate the viscous shear stress for the SDU domain, assuming that it would give an acceptable representation of the grout material characteristics. The sensitivity studies are performed using typical yield stress for different viscosities and different elevations of the grout discharge port.

Three-dimensional transient numerical simulations are made for the Saltstone modeling study by taking two modeling approaches. One is the baseline model for a simple Bingham plastic model to perform the initial scoping calculations of the flow patterns and domain size radially spread for different operating conditions. The other is the grout aging model to evaluate the aging impact of the viscous grout materials on the domain size of the radial spreading of the grout for various operating conditions.

The computational domain and meshes defined for the modeling analysis are shown in Figs. 3 and 4 . The number of the established computational meshes for the entire modeling domain is about $2 \times 10^{5}$ nodes. This number was established from sensitivity studies of computational meshes, demonstrating that the mesh size is independent of the solutions within about $1 \%$ uncertainty. Mesh density is significantly higher in the vicinity of the pouring point on the vault floor to capture the high-speed impinging flow behavior related to the air entrainment and uneven grout surfaces. Typical computational meshes used for the modeling analysis are shown in Fig. 4. It is noted that the characteristic mesh dimension is much greater in regions far from the pouring point and other solid wall surfaces to keep the total number of nodes manageable.

A range of operating conditions such as different viscosities and grout discharge elevations was considered to perform the sensitivity calculations for the flow patterns with respect to the baseline modeling results. The modeling cases used for the present transient analysis are summarized in Table 2. 


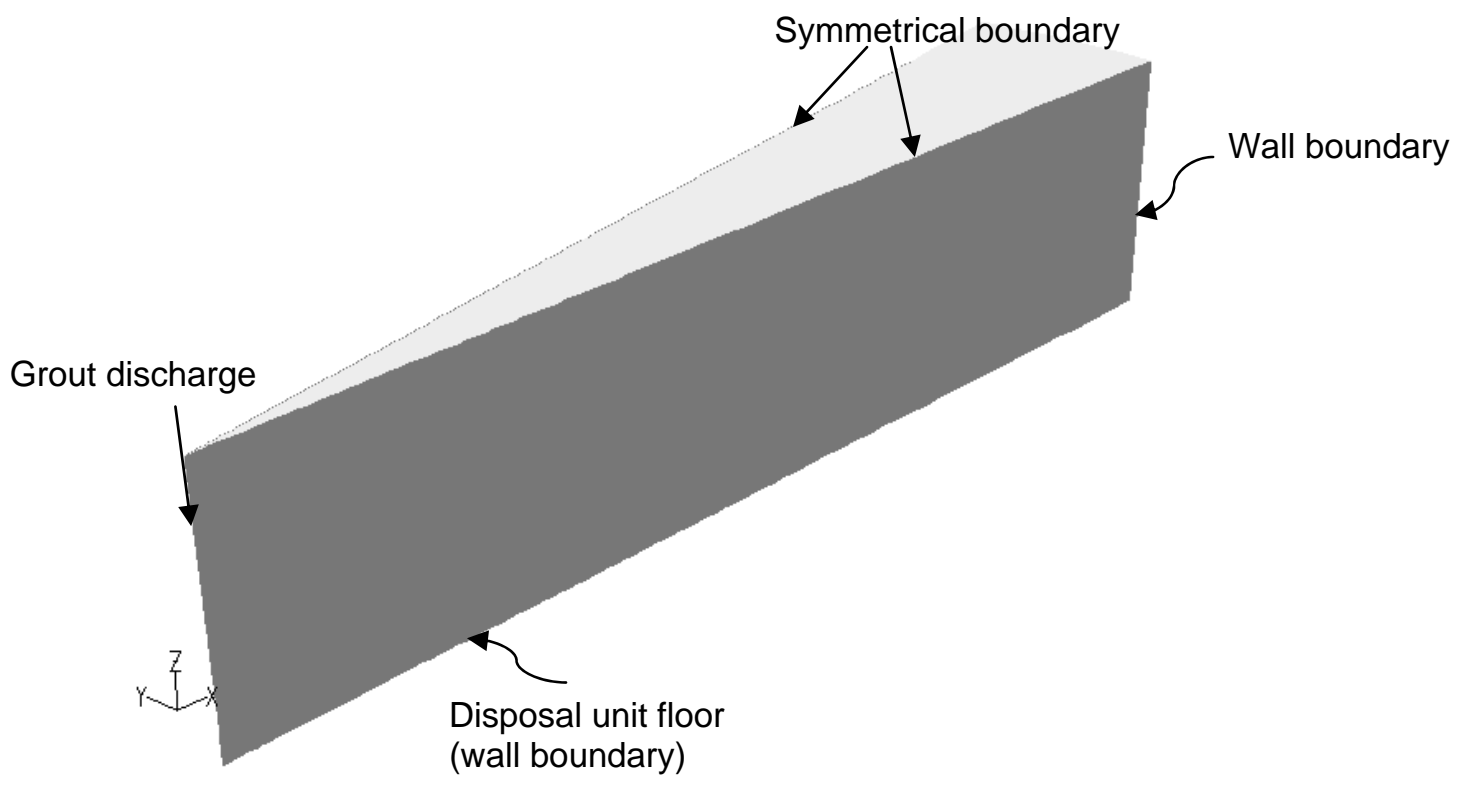

(Computational modeling domain for $10^{\circ}$ sector model)

Figure 3. Computational domain used for the baseline modeling calculations

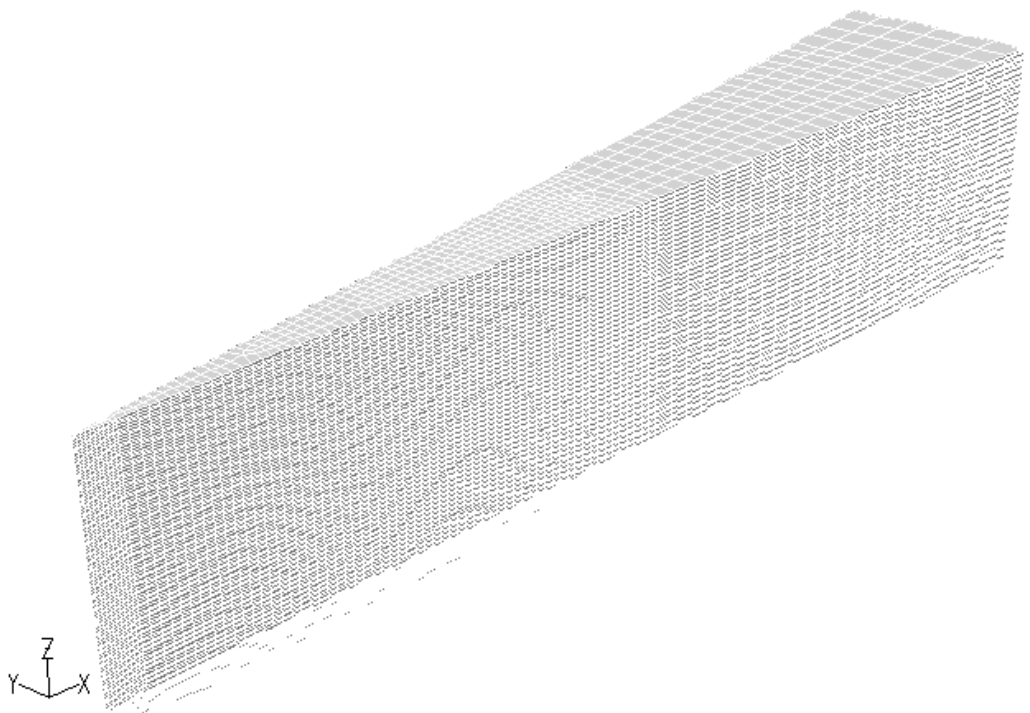

(Computational meshes corresponding to the modeling domain: $2 \times 10^{5}$ nodes)

Figure 4. Three-dimensional hexahedral meshes used for the modeling calculations 


\subsection{RESULTS AND DISCUSSION}

The grout models were developed by a three-dimensional CFD approach to estimate the domain size of the grout materials radially spread on the facility floor and to perform the sensitivity analysis with respect to the baseline design and operating conditions such as elevation height of the discharge port and fresh grout properties. For the CFD modeling calculations, Bingham plastic and time-dependent grout models were considered for examining the impact of fluid spread performance for the initial baseline configurations.

As the performance criteria, the shear rate profile and air contents within the grout material were used as a key indicator of the grout flow movement from the grout pouring region toward the remote wall boundary zone on the facility floor. If the local shear rate for the grout materials gets smaller than $10^{-3}(1 / \mathrm{sec})$, the materials will not be moved adequately and may be eventually solidified. Estimation of flow patterns was used as the degree of grout pouring efficiency from the pouring center to the front edge of the layer. The grout layer accumulated on the floor was estimated from the flow domain of the feed materials obtained by the VOF method for each cell of the computational domain along the fluid movement starting from the material feed inlet. In the analysis, the grout quality was estimated in terms of the grout density formed on the facility floor. In this case, radial spread distance was estimated from the center of grout pouring to the point at which grout volume fraction is higher than 0.1. Benchmarking analysis of the modeling predictions against experimental results is not included in the scope of the work [4].

\subsection{BINGHAM PLASTIC MODELING RESULTS}

As discussed earlier, a Bingham plastic model with $5 \mathrm{~Pa}$ yield stress and $60 \mathrm{cp}$ consistency was used for the baseline performance analysis for basic flow patterns and characteristics associated with radial grout spreading. A three-dimensional CFD two-phase modeling method was used with symmetrical boundary conditions for both side planes of the domain for computational efficiency as shown in Fig. 3. Based on the modeling domain and operating conditions as shown in Fig. 1 and Table 1, transient VOF modeling calculations were performed on the SRNL High Performance Computing (HPC) platform to compute grout flow fields when a $150 \mathrm{gpm}$ flowrate was poured down through a 3-inch pipe at two different elevations, 5 and 43 feet, above the SDU6 floor. Typical computational time was about 6 weeks for the first one-hour transient modeling simulation on a 4 CPU parallel HPC platform. Following the first hour of simulation, another one-hour simulation took about 3 weeks due to the increased time step size required for numerical convergence.

Figure 5 qualitatively compares transient snap shots for grout accumulation results for a 150 gpm feed flow at a $5 \mathrm{ft}$ pouring height. The red zone in the figure indicates $100 \%$ grout volume fraction. The transient results for the Bingham plastic model show that an uneven top surface of the grout layer accumulated around the pouring center of the disposal unit floor is established in about 30 minutes' pouring time. When grout material is poured down at $150 \mathrm{gpm}$ flowrate, $6.81 \mathrm{ft} / \mathrm{sec}$ velocity, through a 3 in discharge pipe from 5 feet above the floor, Figure 6 shows flow patterns and profiles of grout volume fraction and viscosity near the center of the grout pouring at 30 minutes transient time. The results show that the grout layer for $5 \mathrm{ft}$ pouring height has smooth surface except for the central region of about $2 \mathrm{ft}$ radial distance from the impinging point on the dry SDU floor. 
When grout is pouring down from the different heights of $5 \mathrm{ft}$ and $43 \mathrm{ft}$ above the disposal floor, Figure 7 compares transient shapes of the grout accumulation layer near the pouring center for the different pouring heights at 30 minutes' transient time in a qualitative way. The modeling results show that when heavy grout material of $1.7 \mathrm{~g} / \mathrm{ml}$ is pouring down toward the floor of the disposal unit, maximum speeds of about $6 \mathrm{~m} / \mathrm{sec}$ for a $5 \mathrm{ft}$ pouring height and $16 \mathrm{~m} / \mathrm{sec}$ for a $43 \mathrm{ft}$ height are reached just before grout impingement on the floor. Thus, when the grout discharging port becomes higher, the grout impinging speed on the disposal floor becomes higher. The higher impinging speed causes the grout layer near the dropping region to become less smooth as shown in Fig. 7 . It is clearly indicated that rough grout surface is formed near the central spot of the pouring because of high impinging speed of the grout material on the facility floor. As a grout layer accumulated on the floor of storage vault becomes higher with pouring time increased, grout splashing and impinging on the floor can result in air being drawn into the grout zone of the layer as shown in the figures. This can cause degradation of grout quality for the accumulation layer.

For a $150 \mathrm{gpm}$ flowrate poured down through 3-inch pipe at two different elevations, 5 and 43 feet, above the disposal floor, a comparison of transient radial distances from the pouring center between the two different pouring heights during early transient period is presented in Fig. 8. The modeling results clearly show that when the discharge port is located at a higher position, less smooth grout layer is formed below the discharge port at the early transient time less than 30 minutes due to the higher impinging momentum on the floor, resulting in higher air volume trapped inside the grout layer.

When grout pouring time increases, the grout materials are continuously accumulated near the center of pouring, resulting in a more smooth shape of the mound layer. Figure 9 presents a comparison of the transient shape of the grout layer accumulated near the impinging point for a $43 \mathrm{ft}$ pouring height. The red region in the figure represents $100 \%$ grout. Table 3 quantitatively compares thicknesses of the grout accumulation layer between the two discharge heights of 5 and 43 feet at a 3-ft radial distance from the pouring center for various pouring times. Comparison of transient radial distances is made for two different pouring heights as shown in Fig. 10. It is noted that when a grout flow of $150 \mathrm{gpm}$ discharges downward at the $43 \mathrm{ft}$ height, the accumulated layer near the impinging point is established smoothly after the 1 hour transient time, and its layer thickness and shape become very similar to those of the $5 \mathrm{ft}$ discharge case.

As discussed previously, volume of fluid method is employed to predict the grout surface flow accumulated on the horizontal floor. This method is based on the concept of a fractional VOF, which is usually incorporated into the flow equations to track free grout surface. The equations were discretized using the finite volume method as shown in Fig. 4. Figure 11 compares distributions of transient grout volume fractions for a $5 \mathrm{ft}$ pouring elevation along the vertical distance from the floor at the radial distance of one meter (about $3 \mathrm{ft}$ ). As shown in the figure, the top surface of the grout layer settled on the disposal floor has a transition region, which is dependent on pouring time. When the grout discharge port is changed from 5 to 43 feet high above the floor, the transient grout volume fractions for the two different heights of pouring are compared along the vertical distance from the floor at the radial distance of one meter as shown in Fig. 12. Figure 13 presents a comparison of transient grout volume fractions for two different heights of pouring port along the horizontal radial distance from the pouring center at the 0.5 inches above the floor. As mentioned previously, the impact of different grout pouring heights on the grout quality for the layer accumulated on the SDU6 floor was evaluated by grout volume fraction for the present preliminary work. Table 4 shows quantitative comparison of transient grout volume fractions for the grout layer for the two different pouring heights of $5 \mathrm{ft}$ and $43 \mathrm{ft}$. 
The baseline results for the $5 \mathrm{ft}$ pouring height show that when the $150 \mathrm{gpm}$ grout flow with a $5 \mathrm{~Pa}$ yield stress and a $60 \mathrm{cP}$ viscosity is poured down through a 3-in discharge port, the grout is spread radially up to about $64 \mathrm{ft}$ distance from the pouring center after 2 hours' pouring time. The air volume of the grout layer for 5 minutes' transient time has about $71 \%$ at 5 minutes' transient time, and it is reduced by about $9 \%$ in 2 hours' pouring time, resulting in the nominal grout density consisting of about $80 \%$ grout and $20 \%$ air volume fractions. The sensitivity results clearly indicate that the radial spread for the $43 \mathrm{ft}$ discharge port is about 10\% faster than that of the $5 \mathrm{ft}$ discharge port for the early transient period of 5 minutes. It is noted that when the pouring height for $150 \mathrm{gpm}$ flow increases from $5 \mathrm{ft}$ to 43 $\mathrm{ft}$, the grout layer formed during the early transient period contains void volume about $10 \%$ higher than the lower pouring height as shown in Table 4. However, for the pouring time longer than half an hour, an increased grout height placement has an insignificant impact on the radial spread rate and the trapped air volume associated with grout quality as shown in Fig. 10 and Table 4. 


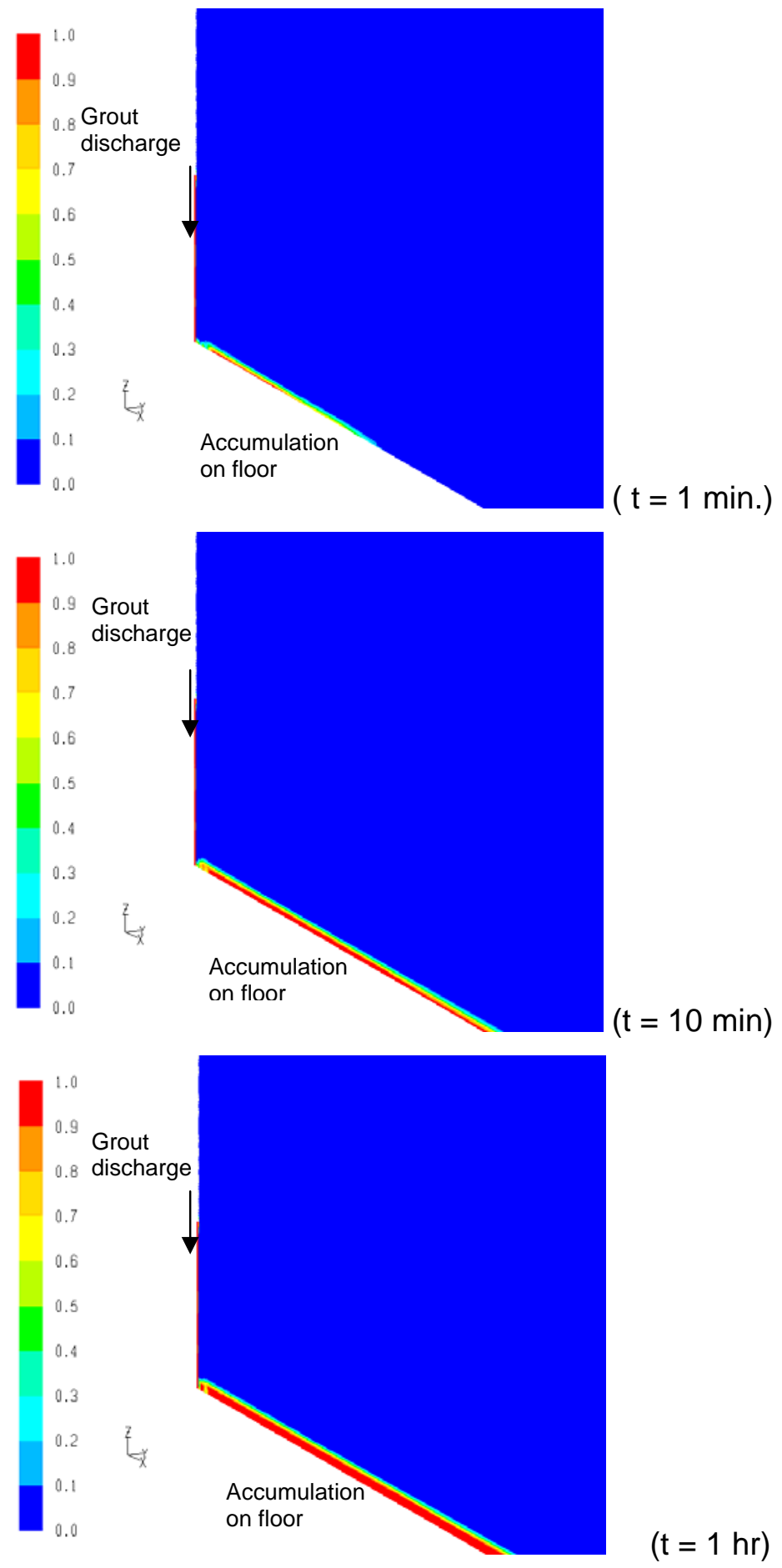

Figure 5. Comparison of transient grout accumulation results for $150 \mathrm{gpm}$ feed flow at $5 \mathrm{ft}$ pouring height, indicating that red zone has $100 \%$ grout volume fraction. 


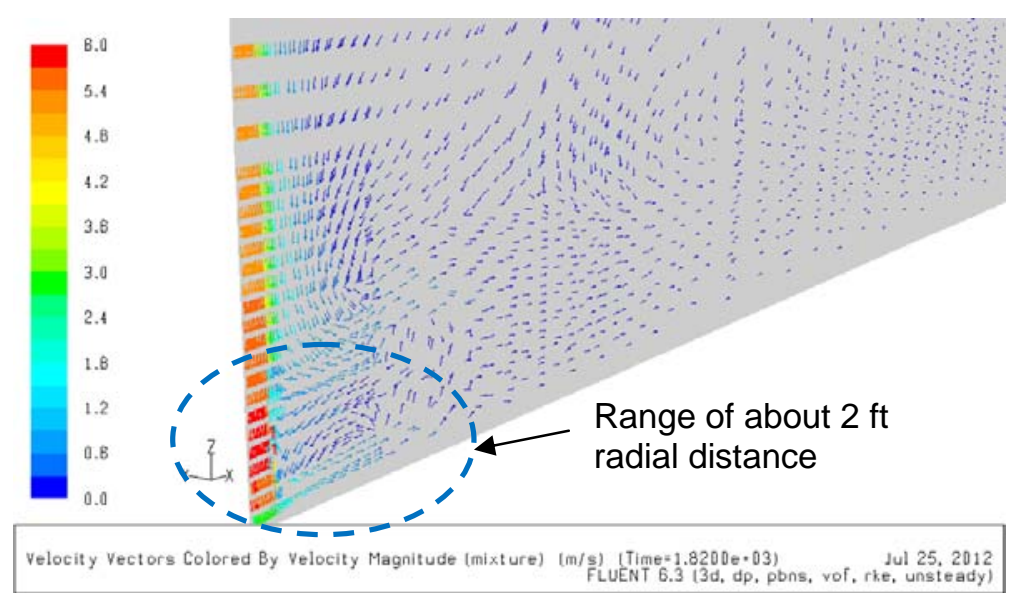

(Flow patterns: Red for velocity higher than $6 \mathrm{~m} / \mathrm{sec}$, blue for very low velocity)

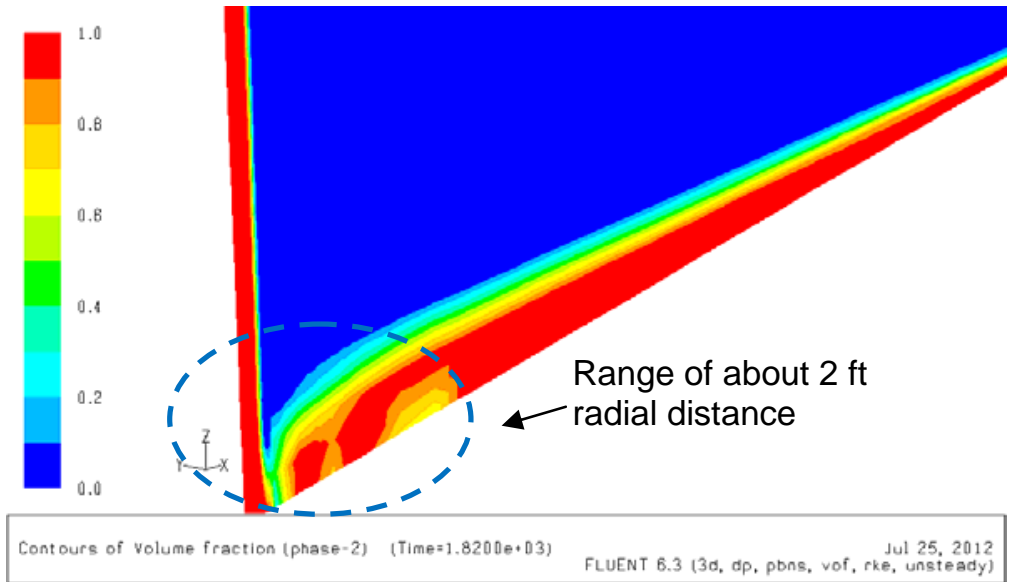

(Grout volume fractions: Red for 100\% grout, blue for 0\% grout)

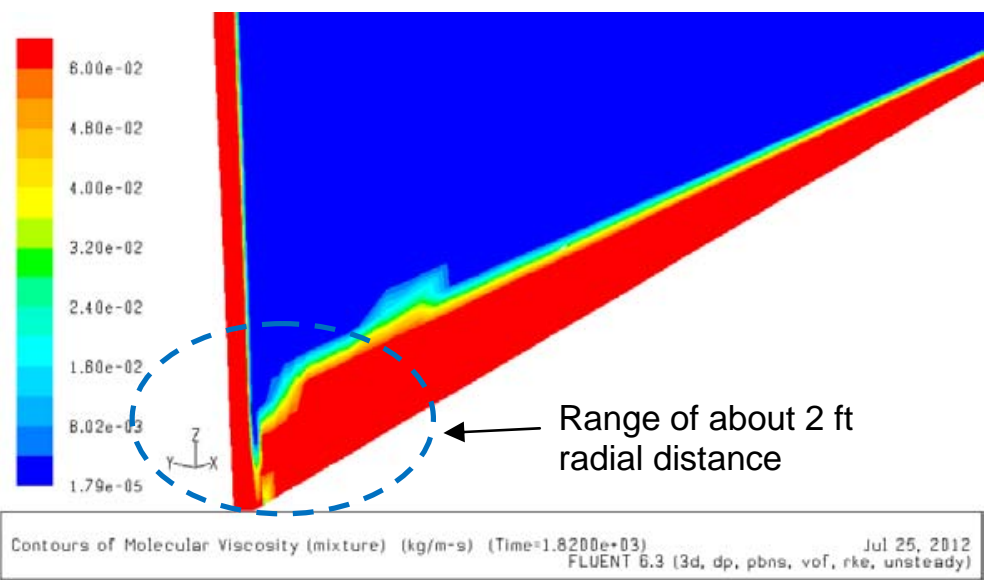

(Mixture viscosity: Red for material viscosity higher than 60cp, blue for air viscosity)

Figure 6. Flow patterns and profiles of grout volume fractions and viscosity near the center of the grout pouring region at 30 minutes transient time for $6.81 \mathrm{ft} / \mathrm{sec}$ discharge velocity corresponding to $150 \mathrm{gpm}$ flow from $5 \mathrm{ft}$ elevation above the SDU floor. 

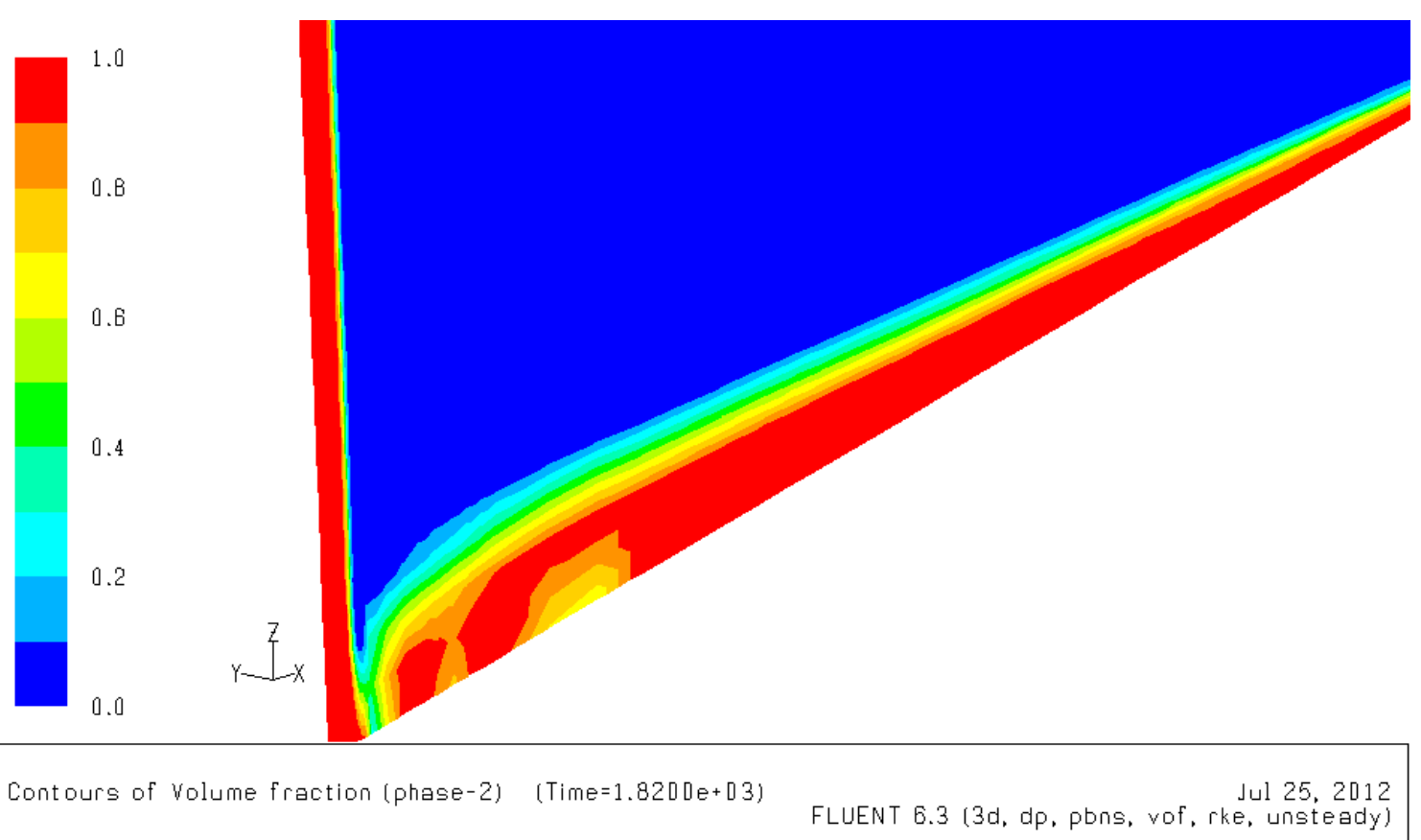

(Grout volume fraction for $5 \mathrm{ft}$ pouring height)

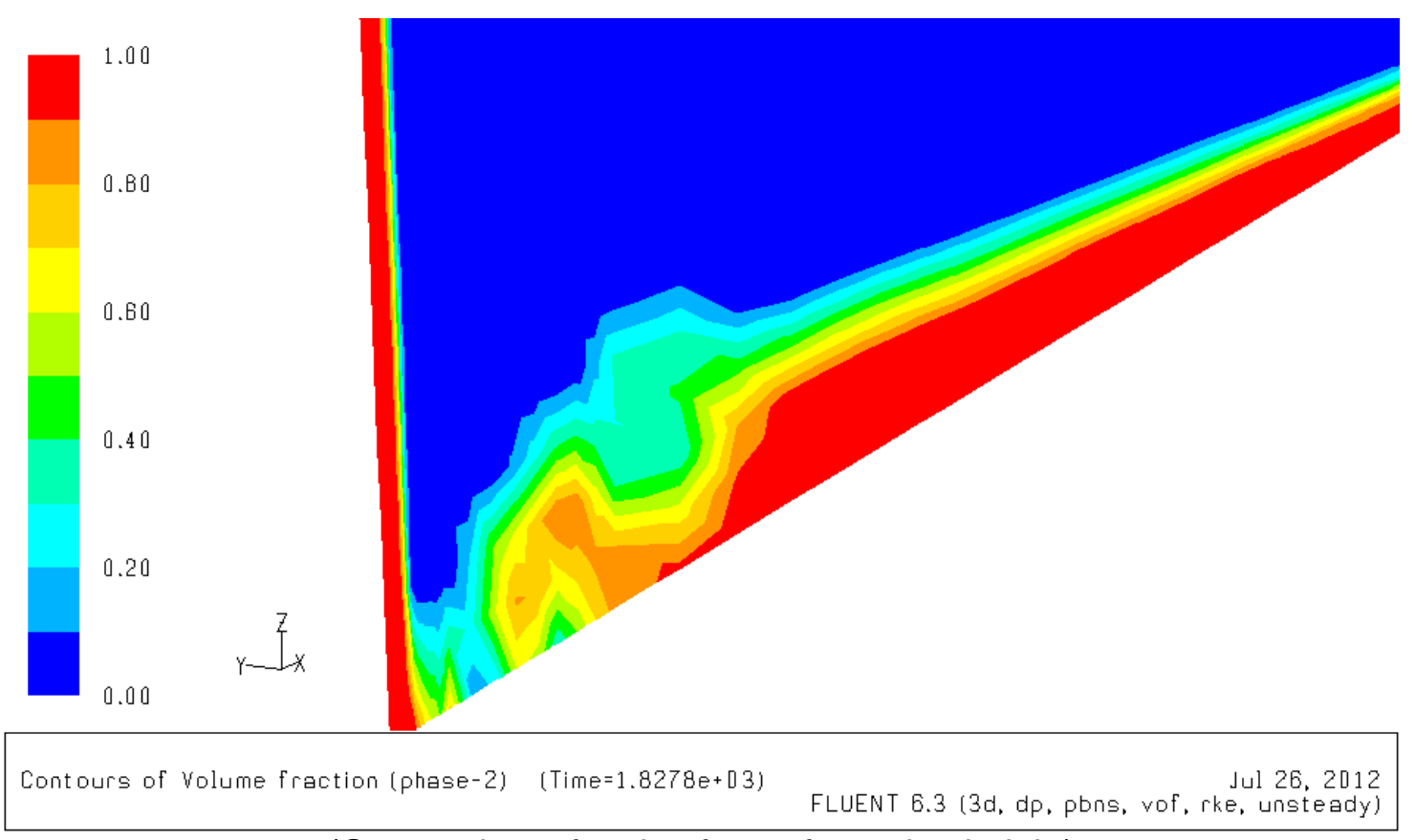

(Grout volume fraction for $43 \mathrm{ft}$ pouring height)

Figure 7. Comparison of transient shapes of the grout layer accumulated on the floor between two different pouring heights near the grout impinging region at 30 minutes' transient time, indicating the red region to be $100 \%$ grout. 


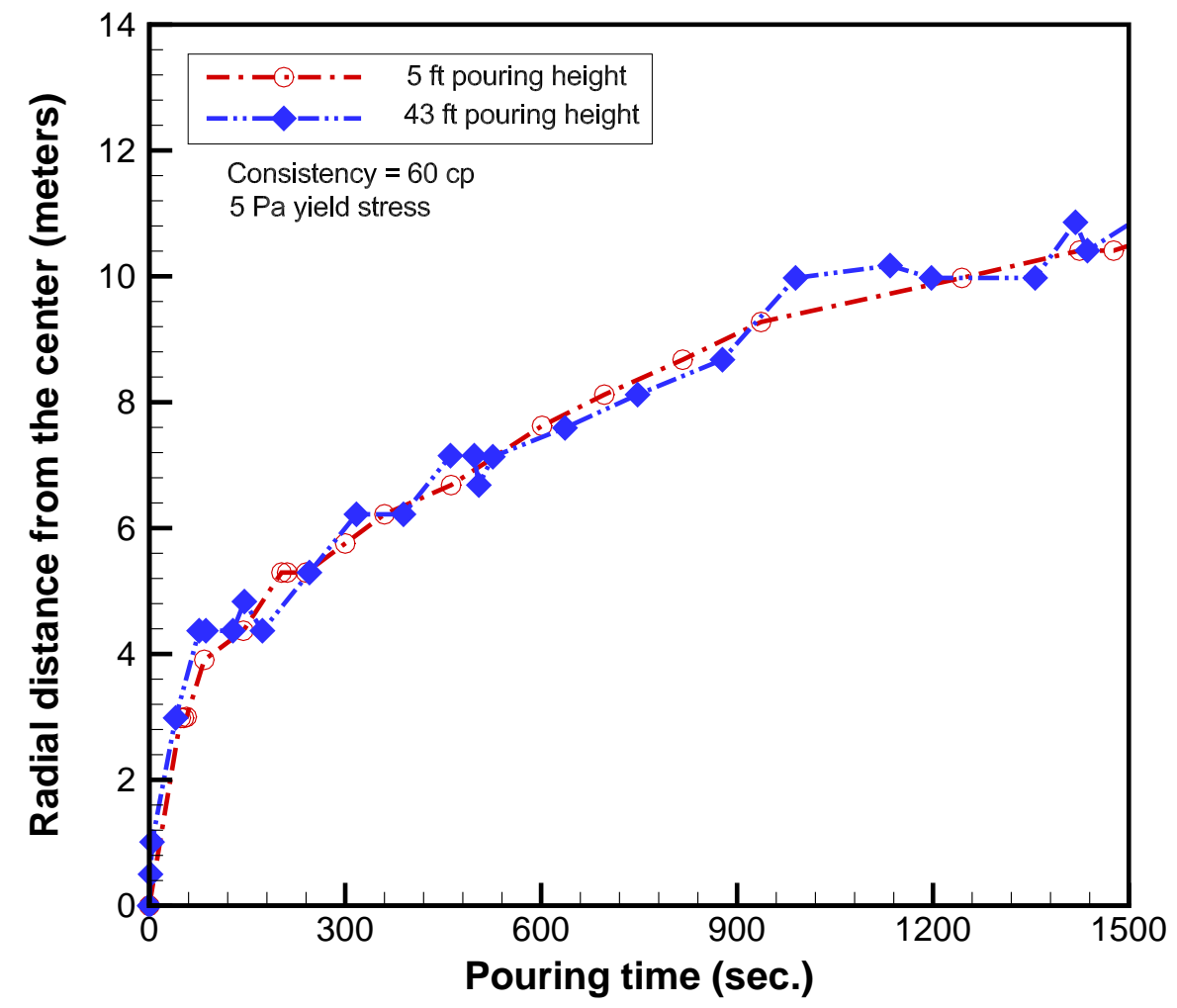

Figure 8. Comparison of transient radial distances from pouring point for two different pouring heights ( $5 \mathrm{ft}$ and $43 \mathrm{ft}$ elevations) during early pouring period. 

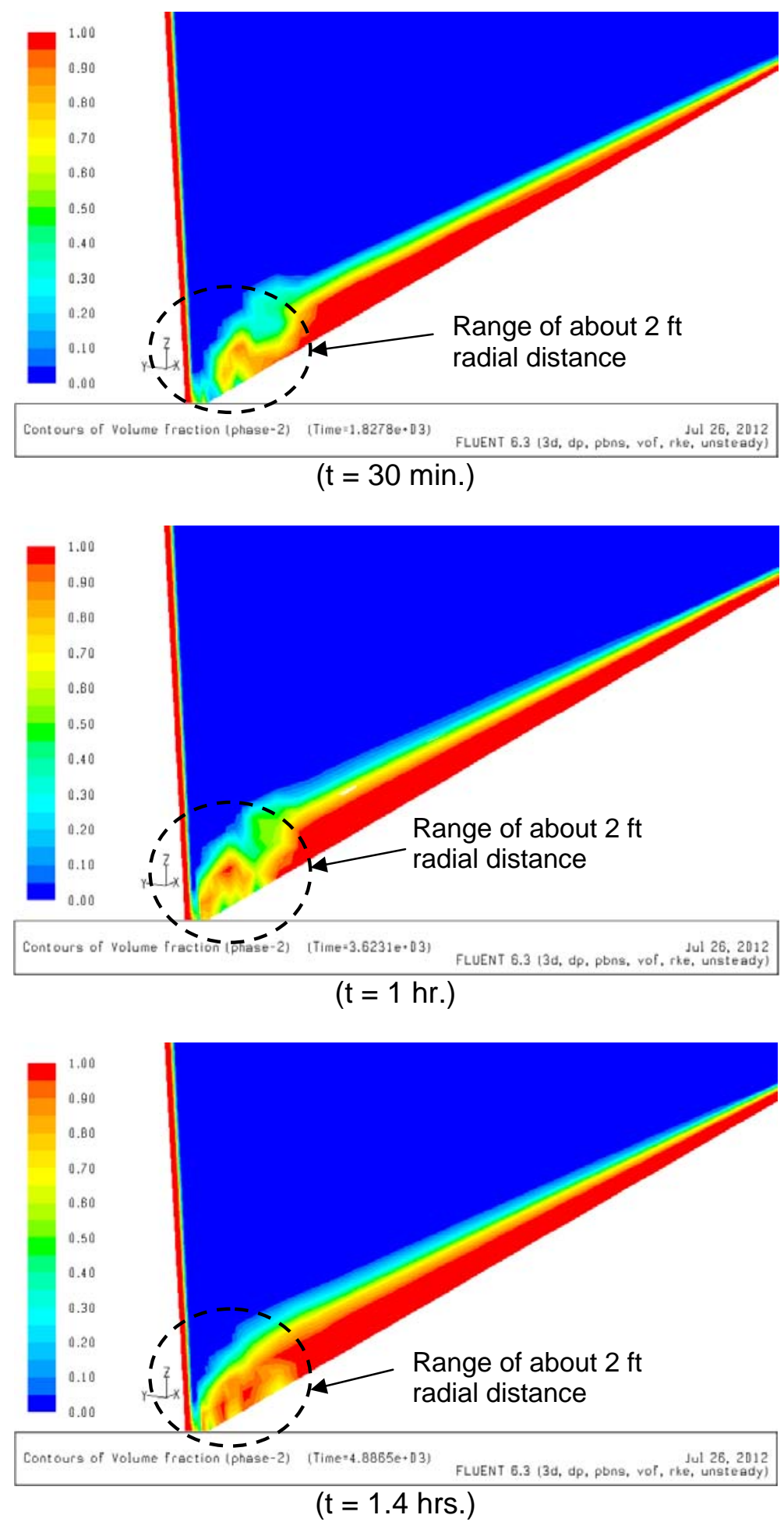

Figure 9. Comparison of transient shape of grout accumulation layer near the pouring point for $43 \mathrm{ft}$ pouring height and $150 \mathrm{gpm}$ grout flowrate. 
Table 3. Comparison of transient accumulation thickness on the SDU floor for two different pouring heights.

\begin{tabular}{|c|c|c|c|c|}
\hline \multirow{2}{*}{$\begin{array}{c}\text { Pouring height } \\
\text { (feet) }\end{array}$} & \multicolumn{4}{|c|}{$\begin{array}{r}\text { Layer thickness* accumulated on the floor at 1-meter radial } \\
\text { distance for different pouring times (inches) }\end{array}$} \\
\cline { 2 - 5 } & $5 \mathrm{~min}$. & $30 \mathrm{~min}$. & $1 \mathrm{hr}$ & $2 \mathrm{hrs}$ \\
\hline 5 & 0.60 & 1.04 & 2.44 & 2.54 \\
\hline 43 & 1.22 & 1.53 & 2.44 & 2.54 \\
\hline
\end{tabular}

Note:* Defined as the height where grout volume fraction is higher than $99 \%$

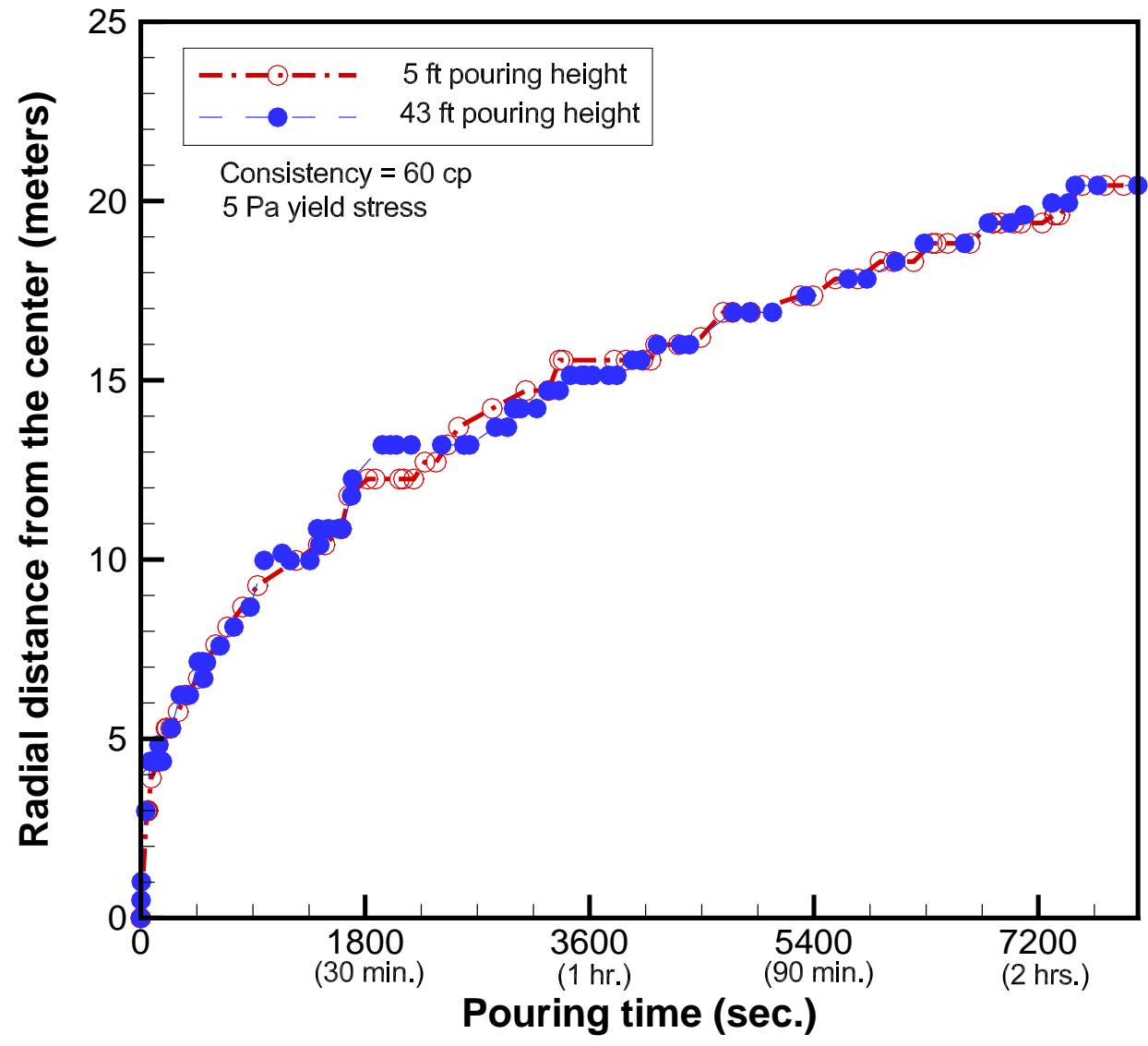

Figure 10. Comparison of transient radial distances from pouring point for two different pouring heights ( $5 \mathrm{ft}$ and $43 \mathrm{ft}$ elevations). 


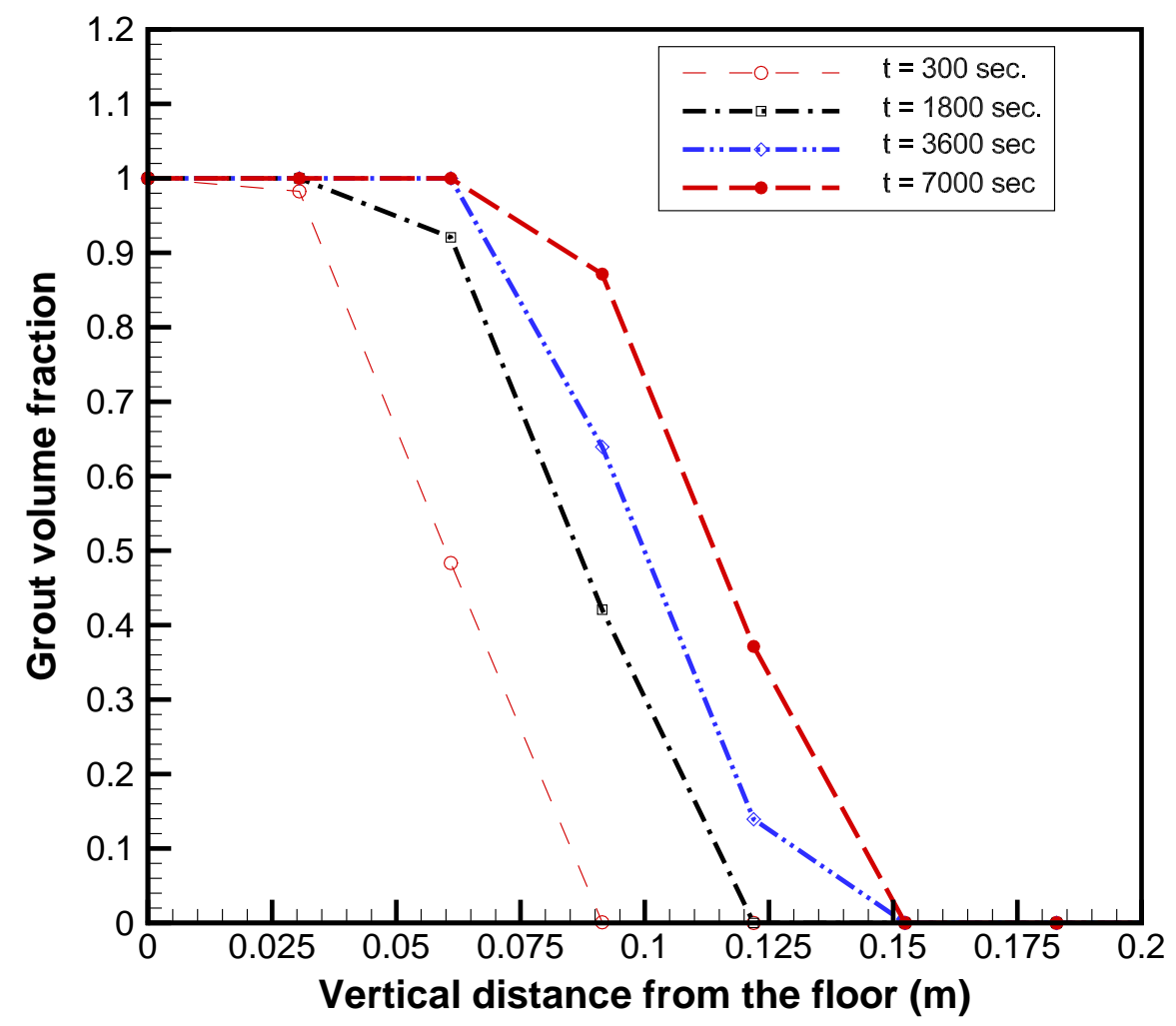

Figure 11. Comparison of transient grout volume fractions for $5 \mathrm{ft}$ pouring elevation along the vertical distance from the floor at the radial distance of one meter. 


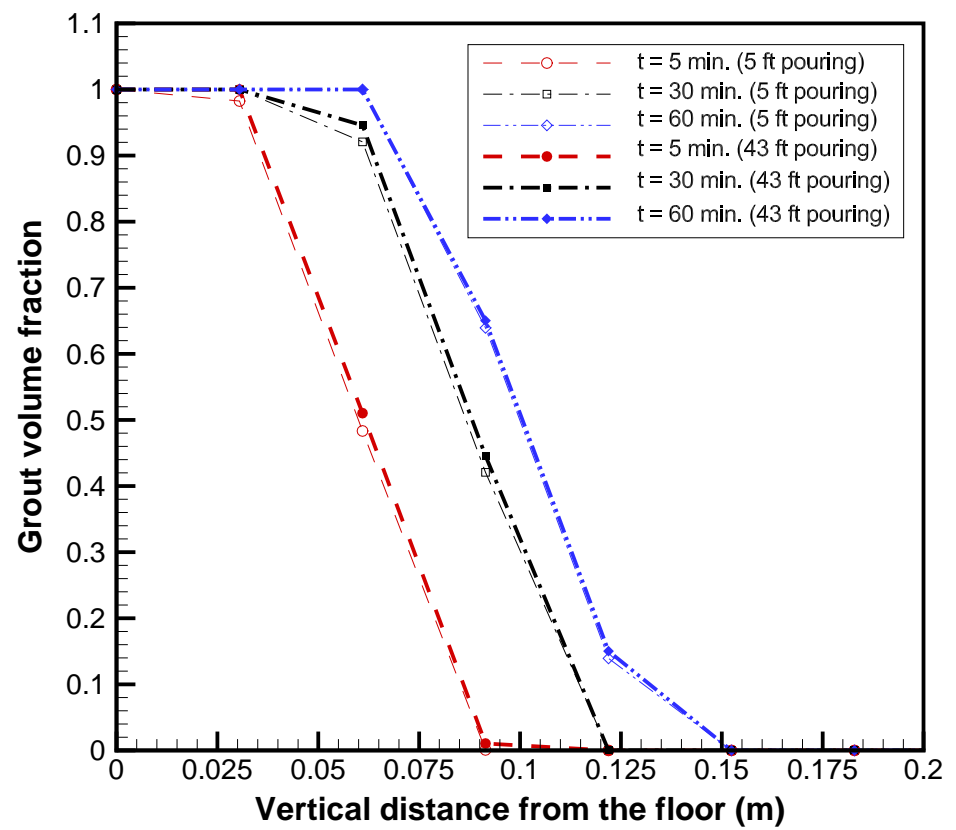

Figure 12. Comparison of transient grout volume fractions for two different heights of pouring port along the vertical distance from the floor at the radial distance of one meter.

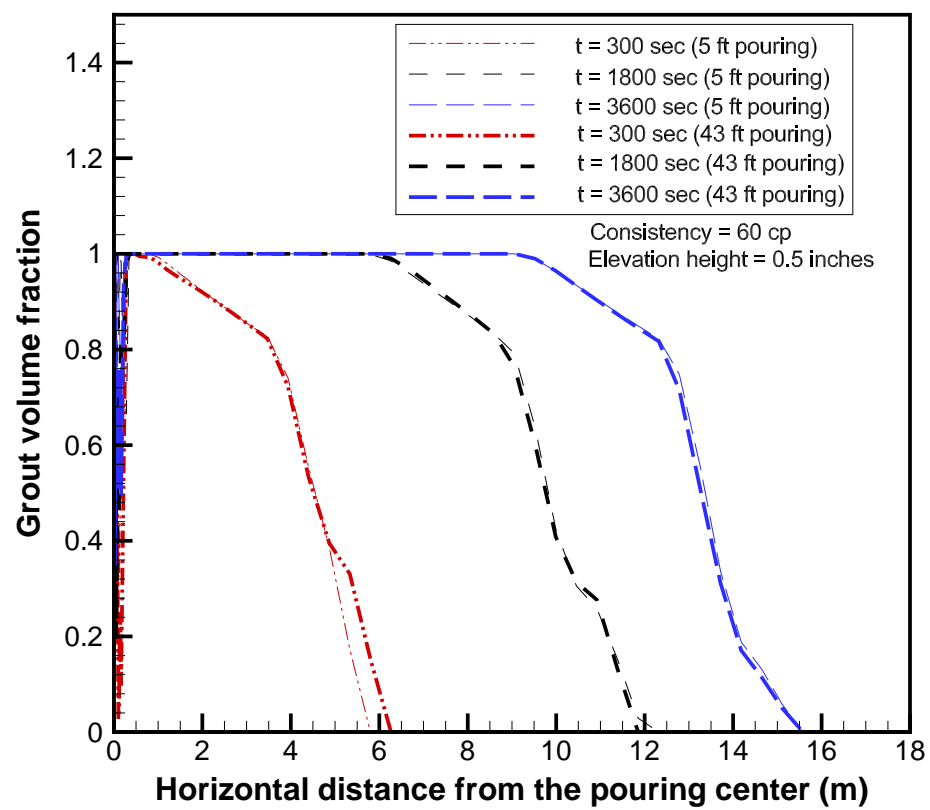

Figure 13. Comparison of transient grout volume fractions for two different heights of pouring along the horizontal distance from the pouring center at 0.5 inches above the floor. 
Table 4. Comparison of transient grout volume fractions for the grout layer on the SDU floor for two different pouring heights.

\begin{tabular}{|c|c|c|c|c|}
\hline \multirow{2}{*}{$\begin{array}{c}\text { Pouring height } \\
\text { (feet) }\end{array}$} & \multicolumn{4}{|c|}{$\begin{array}{c}\text { Grout volume fractions* for the grout layer accumulated on the } \\
\text { floor at 1-meter radial distance for different pouring times }\end{array}$} \\
\cline { 2 - 5 } & $5 \mathrm{~min}$. & $30 \mathrm{~min}$. & $1 \mathrm{hr}$ & $2 \mathrm{hrs}$ \\
\hline 5 & 0.71 & 0.78 & 0.79 & 0.80 \\
\hline 43 & 0.66 & 0.74 & 0.78 & 0.80 \\
\hline
\end{tabular}

Note:* Defined as the area-averaged volume fractions for grout height where grout volume fraction is higher than $10 \%$ at $1-\mathrm{m}$ radial distance

\subsection{GROUT AGING MODELING RESULTS}

The modified Bingham plastic behavior of grout such as thixotropy, i.e., time-dependent viscosity behavior, was modified for conducting the initial scoping calculations to assess the impact of fluid aging on radial spreading and basic flow patterns. The model was proposed by Roussel et al. (2007) by modifying the Bingham plastic model for concrete flow, referred to as the Grout Aging Model in this report. As discussed previously, the modified model includes two additional intrinsic parameters: the structuration rate of the cement mixture at rest and a de-structuration parameter. The structuration state of grout evolves through the flow history. Thus, we calculated the age-of-fluid, i.e., time elapsed after pouring through the nozzle, which can be used for predicting the flow history in a Lagrangian way. From Eq. (8), the structuration rate $\lambda$ was calculated with zero initial value in terms of fluid residence time. For the calculations, thixotropic and transient constants related to the structuration rate are $0.01 \mathrm{~Pa} / \mathrm{sec}$ and 0.1 , respectively.

A transient computational fluid dynamics (CFD) modeling approach was taken for the estimate of radial flow patterns on the SDU6 floor, which was governed by thixotropic Bingham plastic behavior. The modeling domain used for the calculations is shown in Fig. 1. The diameter of the tank is $375 \mathrm{ft}$, and the inlet nozzle is located at $43 \mathrm{ft}$ or $5 \mathrm{ft}$ height from the bottom of the tank. The tank domain was divided into three regions for more stable simulation - i.e., near inlet region, developing region, and far region. These three regions are divided into small control volumes (i.e., nodes or meshes) for CFD simulations. The near inlet region, the developing, and the far regions have 8000, 153,500, and 2500 elements, respectively, and the total number of elements is 164,000 .

The time steps used for the transient simulations vary from $1.0 \times 10^{-4}$ to 0.1 seconds. At the beginning of the pouring process (i.e., $\mathrm{t}<20$ seconds), it is required to have a smaller time step (i.e., $1.0 \times 10^{-4}$ seconds) to achieve a stable converging simulation. However, it was possible to increase time steps when the grout flow was established including impingement of the grout on the bottom floor of the tank and the grout splashing in a radial direction. For the modeling analysis, continuity, momentum, turbulent kinetic energy, and vorticity equations were solved. In addition, the age of the grout was calculated using a convectivediffusive equation with zero diffusivity to calculate the time-dependent viscosity. Total CPU 
hours for transient simulation up to 1800 seconds took about $360 \mathrm{CPU}$ hours. The simulations were performed on a Dell Precision $7500(3.47 \mathrm{GHz}$ Intel Xeon CPU, 24 GB RAM) in the Engineering Computational Laboratory at Mercer University.

A sensitivity analysis for grout pouring height and viscosity under the aging fluid model was performed. As shown in Fig. 14, transient radial distances from the pouring point are compared for two different pouring heights of $5 \mathrm{ft}$ and $43 \mathrm{ft}$ above the disposal unit floor under two different non-Newtonian models of idealized Bingham plastic model and grout aging model. The results show that when values of $0.01 \mathrm{~Pa} / \mathrm{sec}$ for the thixotropic constant and 0.1 for the viscosity time constant in Eq. (9) are used, the overall transient behaviors for the two models are similar, but the thixotropic grout aging model predicts a radial distance about 10\% higher than the idealized Bingham plastic model during the first half an hour period. As mentioned previously, it is emphasized that experimental validation of the modeling predictions is not included in the current work scope.

When grout viscosity increases from $60 \mathrm{cp}$ to $120 \mathrm{cp}$ for two different pouring heights (5 ft and $43 \mathrm{ft}$ elevations) under the thixotropic model, the radial spread rate for the higher viscosity grout is much slower than that of the lower viscosity grout. A quantitative comparison for the two pouring heights is shown in Fig. 15. When the fresh grout viscosity increases from $60 \mathrm{cp}$ to $120 \mathrm{cp}$ for a fixed pouring height of $5 \mathrm{ft}$ above the disposal floor, the thickness of the layer accumulated on the floor becomes higher because of the increased viscosity as shown in Figs. 16 and 17. A quantitative comparison of the grout volume fractions averaged along the vertical direction at $8.25 \mathrm{ft}$ radial distance between the two different viscosities is presented in Fig. 18. The transient modeling results clearly show that when the grout becomes more viscous, the thickness of the grout layer accumulated on the floor becomes higher and the radial spread distance becomes smaller because of the slower movement. It is noted that as grout becomes more viscous, average void volume for the grout layer at a given radial distance becomes smaller for the slower movement along the radial direction. 


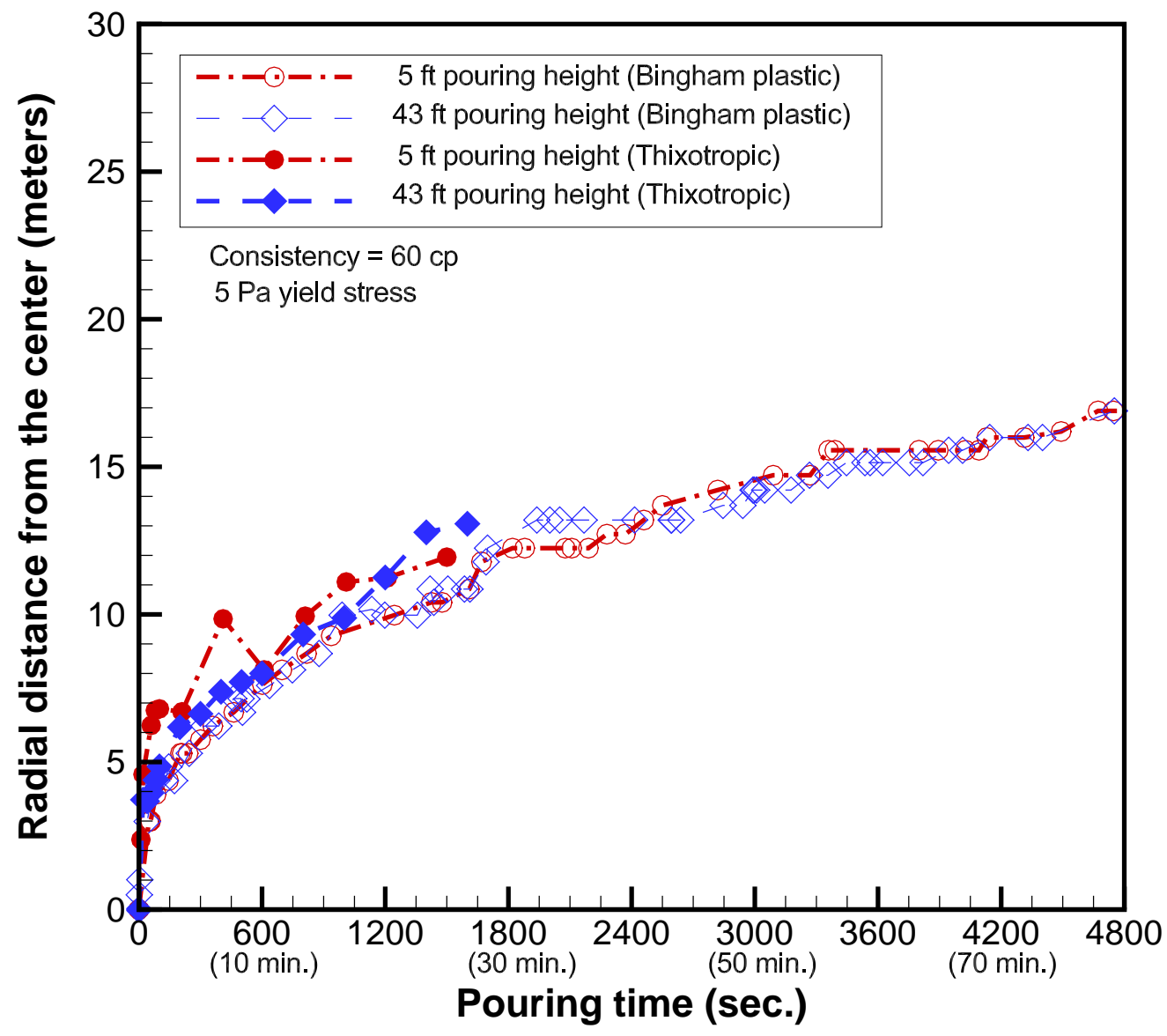

Figure 14. Comparison of transient radial distances from pouring point for two different pouring heights ( $5 \mathrm{ft}$ and $43 \mathrm{ft}$ elevations) under two different non-Newtonian models. 


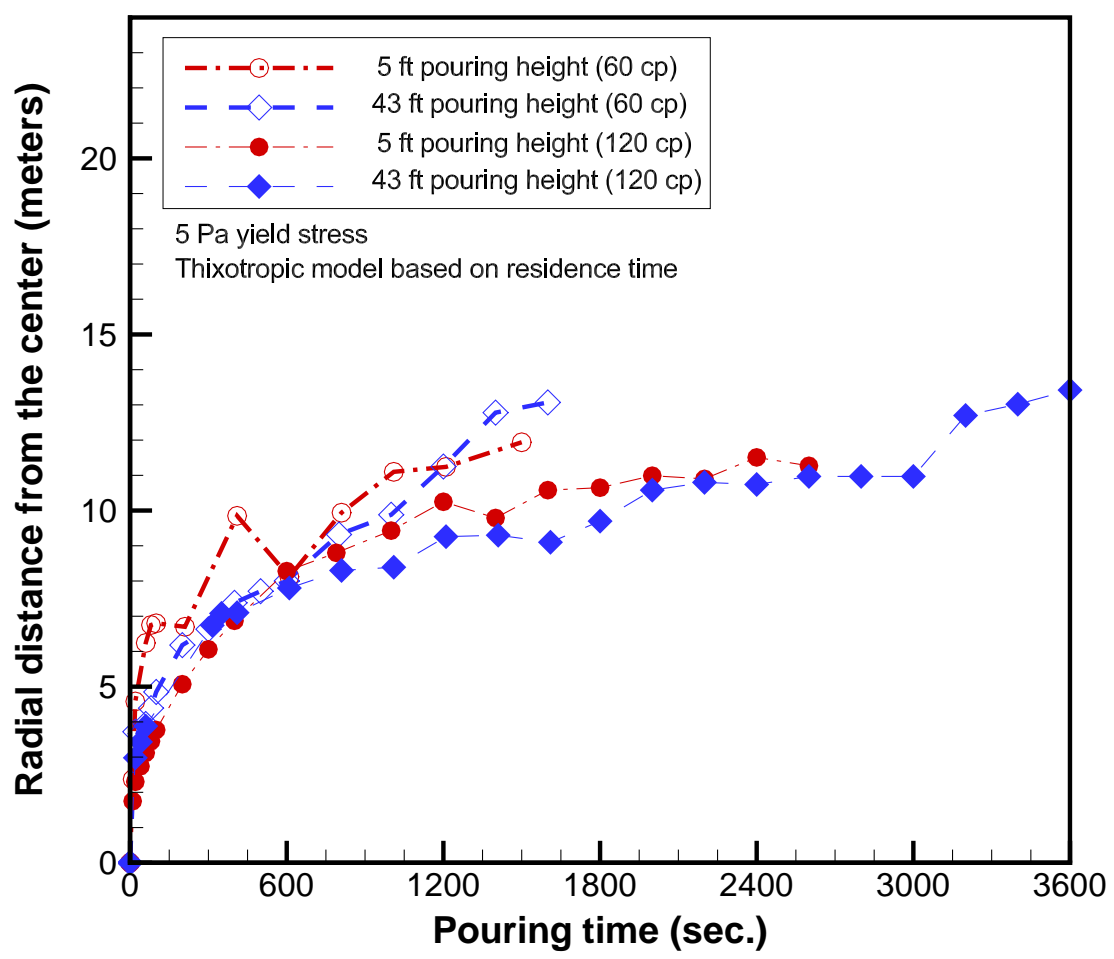

Figure 15. Comparison of transient radial distances for two different pouring heights $(5 \mathrm{ft}$ and $43 \mathrm{ft}$ elevations) for different viscosities from grout thixotropic model.

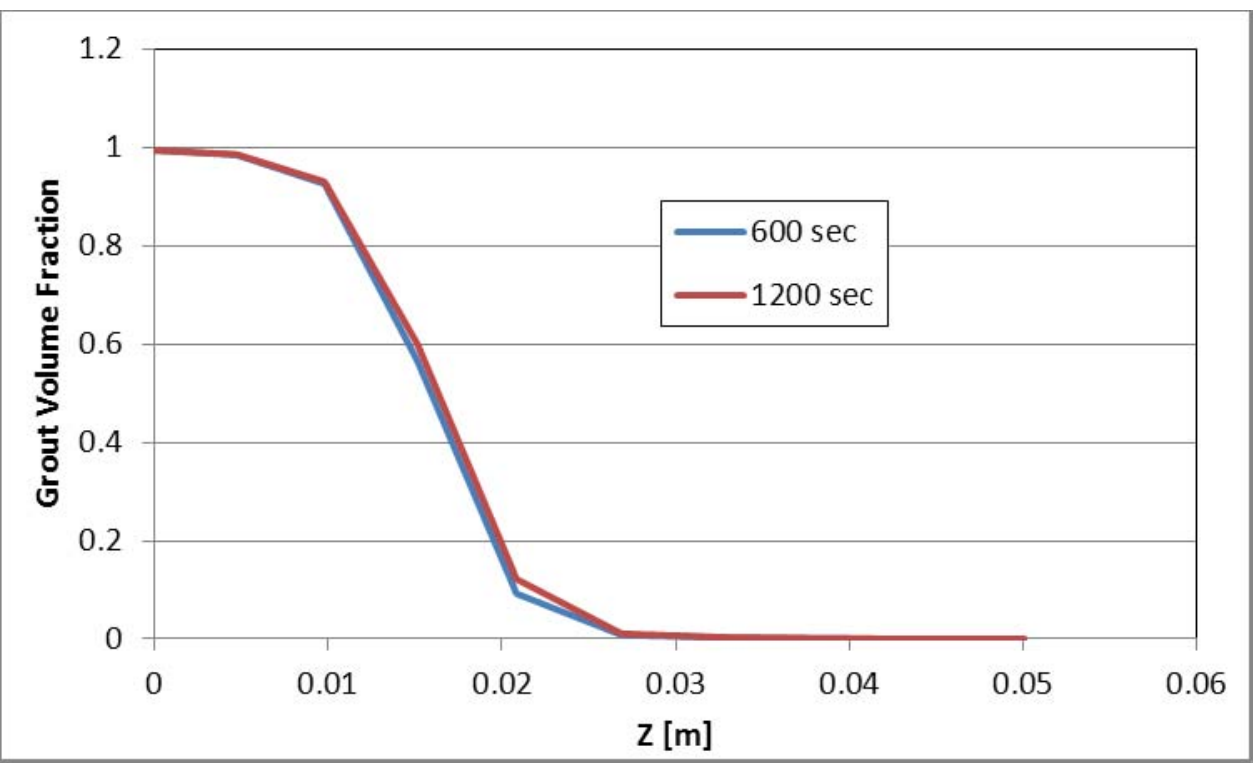

Figure 16. Distribution of grout volume fraction along the vertical line at $r=8.25 \mathrm{ft}$ from the center for $5 \mathrm{ft}$ pouring elevation and $60 \mathrm{cP}$ nominal viscosity case. 


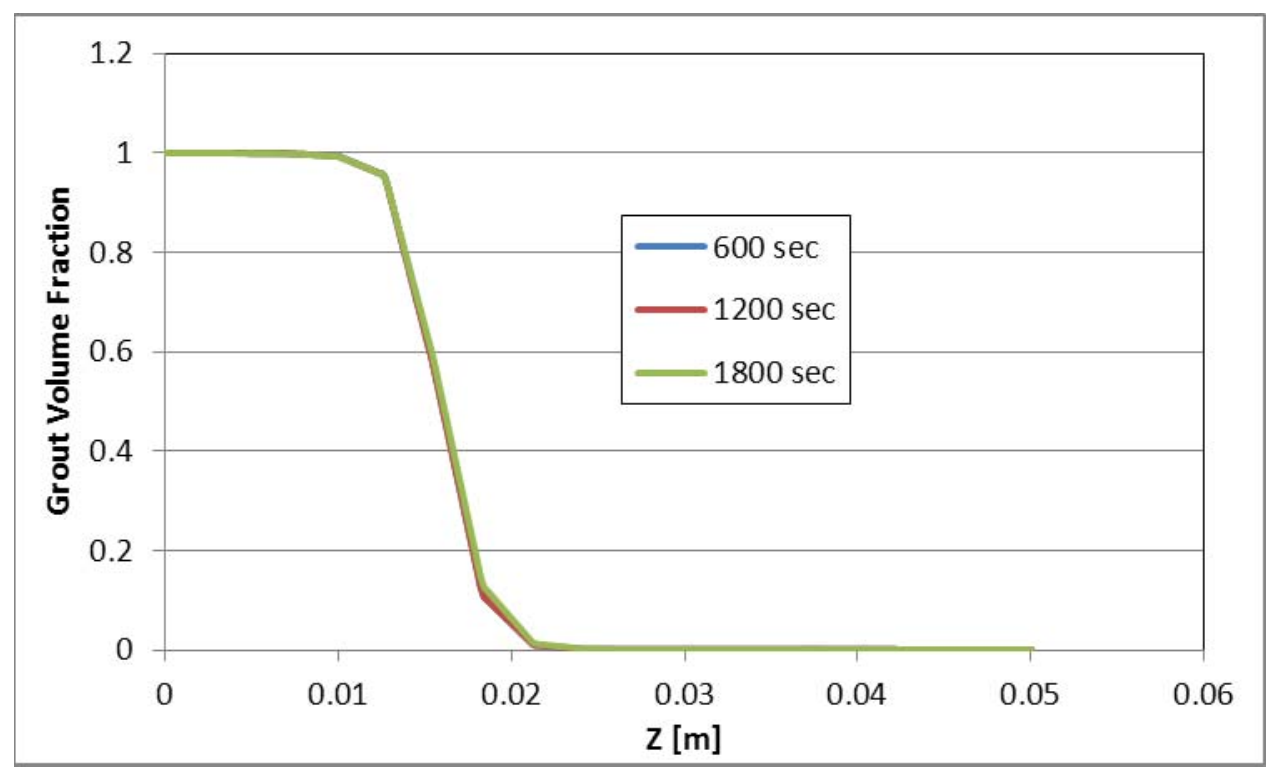

Figure 17. Distribution of grout volume fraction along the vertical line at $r=8.25 \mathrm{ft}$ from the center for $5 \mathrm{ft}$ pouring elevation and $120 \mathrm{cP}$ nominal viscosity case.

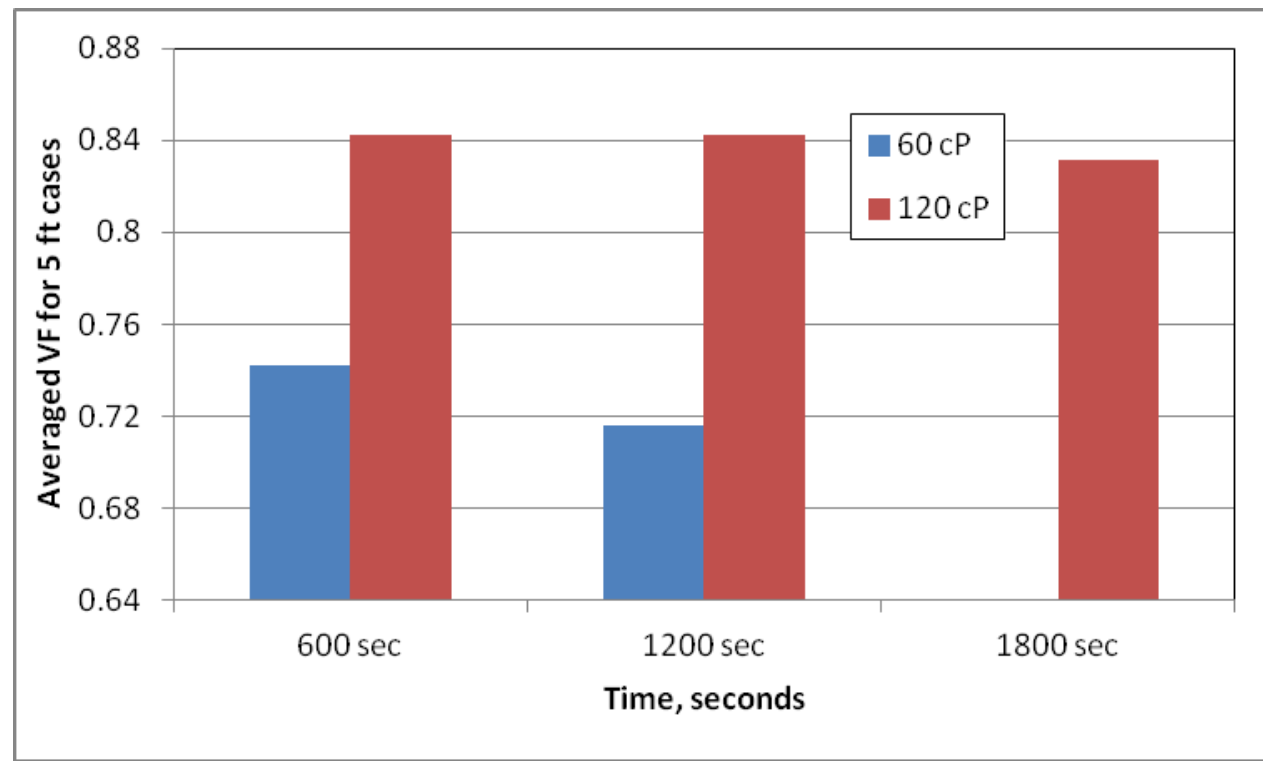

Figure 18. Averaged grout volume fraction comparison between two different viscosity cases. 


\subsection{CONCLUSIONS AND SUMMARY}

Two transient grout models have been developed by taking a three-dimensional CFD approach to estimate the domain size of the grout materials radially spread on the facility floor and to perform the sensitivity analysis with respect to the baseline design and operating conditions such as elevation height of the discharge port and fresh grout properties. For the CFD modeling calculations, Bingham plastic and time-dependent grout models were considered for examining the impact of fluid spread performance for the initial baseline configurations.

As the performance criteria, shear rate profile and air contents within the grout material were used as key indicators of the grout flow movement from the grout pouring region toward the remote wall boundary zone on the facility floor. If the local shear rate for the grout materials is less than $10^{-3}(1 / \mathrm{sec})$, the materials will not be moved adequately and may eventually solidify. Estimation of flow patterns was used as the degree of grout pouring efficiency from the pouring center to prevent uneven mound formation. The grout layer accumulated on the floor was estimated from the flow domain of the feed materials obtained by the VOF method for each cell of the computational domain along the fluid movement starting from the material feed inlet. In the analysis, the grout quality was estimated in terms of the grout volume fraction formed on the facility floor. In this case, radial spread distance was estimated from the center of grout pouring to the point at which grout volume fraction is higher than 0.1. The modeling results should be considered as scoping calculations since the model was not validated against test results.

A series of sensitivity calculations for different pouring heights and operating conditions have been performed to provide operational guidance for grout pouring in a 375-ft SDU6 facility. In the analysis, the viscous shear was modeled by using the Bingham plastic approximation and transient thixotropic behavior of fresh grout material. Transient analyses with a Bingham plastic model were performed with the FLUENT ${ }^{\mathrm{TM}}$ code on the high performance parallel computing platform at SRNL. The analysis coupled with a transient grout aging model was performed by using ANSYS-CFX code on a parallel computing platform at Mercer University. All analyses were based on three-dimensional results. Recommended operational guidance was developed assuming that local shear rates and flow patterns related to radial spread along the SDU floor can be used as a measure of grout performance and spatial dispersion affected by the grout height and viscosity. The grout quality was estimated in terms of the grout volume fractions formed on the facility floor, leading to the change of grout density.

The main conclusions drawn from the grout modeling and calculations are as follows:

- The baseline results for the $5 \mathrm{ft}$ pouring height show that when the $150 \mathrm{gpm}$ grout flow with a $5 \mathrm{~Pa}$ yield stress and a $60 \mathrm{cp}$ viscosity is poured down through a 3-in discharge port, the grout is spread radially up to about $64 \mathrm{ft}$ distance from the pouring center after 2 hours' pouring time. The air volume fraction of the grout layer is about $29 \%$ at 5 minutes' transient time, and it is reduced by about $9 \%$ in 2 hours' pouring time, resulting in the grout density consisting of about $80 \%$ grout and $20 \%$ air volume fractions.

- The sensitivity results show that when the discharge port is located at a higher position, a larger amount of air is trapped inside the layer formed below the discharge port at the early transient time of less than 30 minutes because of the 
higher impinging momentum of the grout flow on the floor, resulting in the formation of less smooth layer.

- The results clearly indicate that the radial spread for the $43 \mathrm{ft}$ discharge port is about $10 \%$ faster than that of the $5 \mathrm{ft}$ discharge port for the early transient period of 5 minutes. However, for the pouring time longer than half an hour, the discharge port height does not affect the radial distance spread on the disposal floor.

- The sensitivity results show that for $150 \mathrm{gpm}$ grout flow from $43 \mathrm{ft}$ height above the floor, the grout layer formed during the early transient period contains the void volume about $10 \%$ higher than the lower pouring height of $5 \mathrm{ft}$. However, for the pouring time longer than half an hour, the discharge port height has insignificant impact on the trapped air volume related to the grout quality.

- A modified Bingham plastic model coupled with time-dependent viscosity behavior was developed for conducting the initial scoping calculations to assess the impact of fluid aging impact on radial spreading and basic flow patterns.

- The results for the transient viscosity model show that when grout material becomes more viscous, the thickness of the grout layer accumulated on the floor becomes higher, but the radial distance spread on the horizontal floor becomes smaller. The early transient results for the grout density with about $32 \%$ air volume fractions are in reasonable agreement with those of the idealized Bingham plastic model.

- It is recommended that the current models developed here be benchmarked against the experimental results for critical applications of the modeling results. In addition, key transient grout material properties such as yield stress, viscosity, and surface tension, closely related to radial spreading and front end height, and transient grout porosities or densities associated with grout quality be experimentally quantified for critical applications of the modeling results.

\subsection{REFERENCES}

1. T. C. Baughman, Saltstone Facility Disposal Unit \#6 Project, Bldg. 451-006Z (U), Task Requirements and Criteria Document, M-TC-Z-00008, Rev. 3 March 28, 2012.

2. G-TTR-Z-00001, Evaluate/Recommend Saltstone Grout and Placement Technical Issues for SDU \#6

3. G-TDP-Z-00001, Saltstone Disposal Unit 6 Technology Development Program Plan

4. S. Y. Lee, "Task Technical and Quality Assurance Plan for Saltstone SDU\#6 Modeling Study (U)", SRNL-RP-2012-00128, April 2012.

5. S. Y. Lee, "Grout Hopper Mixing Study", SRNL-RP-2011-00258, Technical Task Plan, March 2011.

6. A. D. Cozzi, E. K. Hansen, T. M. Jones, and Y. R. Safford, "Bench Scale Saltstone Process Development Mixing Study", SRNL-STI-2011-00346, Revision 0, June 2011.

7. S. Y. Lee and B. W. Armstrong, "SDI CFD Modeling Analysis", SRNL-STI-2011-00025, April 2011.

8. S. Y. Lee, R. A. Dimenna, R. A. Leishear, D. B. Stefanko, "Analysis of Turbulent Mixing Jets in a Large Scale Tank", ASME Journal of Fluids Engineering, Volume 130, Number 1, pp. 011104, 2008.

9. R. A. Dimenna, S. Y. Lee, andD. A. Tamburello, "Advance Mixing Models", SRNL-STI2011-00026, Fubruary 2011. 
10. S. Y. Lee, R. A. Dimenna, R. A. Leishear, and D. B. Stefanko, "Mixing in Large Scale Tanks Part I; Flow Modeling of Turbulent Mixing Jets", HT-FED2004-5622, 2004 ASME Heat Transfer / Fluids Engineering Summer Conference, Charlotte, N. C., July 11-15, 2004.

11. V. E. Schrock, R. T. Revankar, R. Mannheimer, S. Y. Lee, and C-H Wang, "Critical Flow Through a Small Break on a Large Pipe with Stratified Flow", Lawrence Berkeley National Laboratory, LBL-18386, 1985.

12. S. Y. Lee, R. A. Dimenna, J. R. Neuville, and G. A. Taylor, "Erosion Modeling Analysis For DWPF MFT/SME Tanks", WSRC-TR-2003-00345, September 2003.

13. FLUENT, Fluent, Inc., 2003

14. G. B. Tatterson, Fluid Mixing and Gas Dispersion in Agitated Tanks, McGraw-Hill, Inc., 1991.

15. J. Baldyga and J. R. Bourne, "A Fluid Mechanical Approach To Turbulent Mixing and Chemical Reaction, Part III Computational and Experimental Results for the New Micromixing Model", CHEM. Eng. Commun., Vol. 28, pp. 259-281, 1984.

16. W. M. Kays and M. E. Crawford, Convective Heat and Mass Transfer, Second Edition, McGraw-Hill Book Company, New York, 1980.

17. Hinze, J. O., Turbulence, Second Edition, McGraw-Hill, New York, p. 72, 1975.

18. Tennekes, H. and Lumley, J. L., A First Course in Turbulence, The MIT Press, Cambridge, 1972.

19. Roussel N., Geiker M.R., Dufour F., Thrane L.N., and Szabo, P., "Computational modeling of concrete flow: General overview," Cement and Concrete Research, 37, pp 1298-1307, 2007. 